Research Article

\title{
Efficient Investigation of Rock Crack Propagation and Fracture Behaviors during Impact Fragmentation in Rockfalls Using Parallel DDA
}

\author{
Lu Zheng, ${ }^{1,2}$ Yihan Wu, ${ }^{1}$ Wei Wu, ${ }^{3}$ Hong Zhang $\mathbb{D}^{3}$ Xinyan Peng $\mathbb{D}^{2},{ }^{2}$ Xuelue Zhang, ${ }^{1,4}$ \\ and Xuezhen $\mathrm{Wu}^{1}$ \\ ${ }^{1}$ College of Civil Engineering, Fuzhou University, Fuzhou 350108, China \\ ${ }^{2}$ Sichuan University-The Hong Kong Polytechnic University Institute for Disaster Management and Reconstruction, \\ Sichuan University, Chengdu 610207, China \\ ${ }^{3}$ College of Civil Engineering, Tongji University, Shanghai 200092, China \\ ${ }^{4}$ Fujian Provincial Institute of Architectural Design and Research Co. Ltd., Fuzhou 350001, China
}

Correspondence should be addressed to Hong Zhang; hongzhang@tongji.edu.cn and Xinyan Peng; pengxinyan12321@my.swjtu.edu.cn

Received 23 April 2021; Accepted 31 July 2021; Published 31 August 2021

Academic Editor: Faming Huang

Copyright (c) $2021 \mathrm{Lu}$ Zheng et al. This is an open access article distributed under the Creative Commons Attribution License, which permits unrestricted use, distribution, and reproduction in any medium, provided the original work is properly cited.

\begin{abstract}
The study of the rock crack propagation and fracture behaviors during impact fragmentation is important and necessary for disaster evaluation of rockfalls. Discontinuous Deformation Analysis (DDA) incorporating virtual joints can offer a powerful tool to solve such a problem. In the analysis process, the computational efficiency is critical because the mesh must be very dense to make crack propagation more realistic. Thus, parallel DDA using OpenMP is applied. The flattened and precrack Brazilian disc tests are first reproduced, respectively, to verify the accuracy and efficiency of the parallel DDA with virtual joints. Then, the impact fragmentation process is simulated and validated with corresponding laboratory experiments in terms of crack propagation results. Furthermore, the effects of joint-slope angle, joint connectivity rate, and impact velocity on rock fracture behaviors are investigated. It is concluded that the peak number of cracks occurs when the joint-slope angle ranges between $30^{\circ}$ and $45^{\circ}$; the higher impact velocity and joint connectivity rate tend to cause more cracks and larger damages to the specimen.
\end{abstract}

\section{Introduction}

Rockfall is one of the major geohazards in mountainous regions which is capable of threatening human life and properties $[1,2]$. Since many infrastructures such as highspeed roads and railways are constructed inevitably through the area that is susceptible to rockfall, the investigation of development and mobility of rockfall is important [3-7].

Rockfall has been studied for decades $[8,9]$. The researches of rockfall mechanics can be classified into two categories [1]: cause and motion. Rockfall can be triggered by weathering or fracturing of its surrounding $[10,11]$ and other factors like earthquakes [12]. When triggered, the rock will move in several modes of motion [13-15]. In addition, researches about rockfall hazard assessment were also performed $[16,17]$. Experiments are also served as an effective research approach about rockfall [18-20].

Compared to those aspects mentioned above, less attention has been paid to the fragmentation during rockfall [4]. Rockfall fragmentation is commonly observed in both in situ investigations and experimental tests [4, 21]. Fragmentation shows a great influence on the mechanical behaviors of rockfalls, which may greatly alter the trajectory and increase the probability of impact [22-24]. Because the physical fragmentation progress in rockfalls is complex, many computational codes adopted empirical or semiempirical models for the simulation [25]. Various fragmentation consideration approaches have been applied in rockfall 
risk assessment, and most of them incorporate breakage models based on In Situ Block Size Distribution (IBSD) and Rockfall Block Size Distribution (RBSD) [26-29]. In recent years, some scholars tried to reveal the fragmentation mechanism in a physical way. The authors of [30] used the Discrete Element Method (DEM) to study the impact-induced fragmentation in rockfalls and claimed that large fragments are generated only when there are open preexisting fractures or when there are fully persistent closed fractures. De Blasio and Crosta [31] used DEM to study the fragmentation and boosting of rockfalls and rock avalanches. The authors of [32-34] used bond DEM particles to form an intact rock, and the simulation suggested that the collisions with the bottom floor produce fragmentations. Those studies yielded important and inspiring conclusions.

Nevertheless, the physical simulation of fragmentation in rockfalls still needs to be investigated. The rocks used are usually bonded by sphere particles, which can be different from real situations. The preexisting defects of the rock may affect the crack propagation and dynamic behavior of the fragments. Moreover, many studies were focused on the effects of impact loads on the fragmentation, but the internal factors such as preexisting crack have not been thoroughly investigated in mechanic manners. It is important because the existing cracks in rocks may significantly weaken the internal structure and dominate the fragmentation behavior.

To study the effect of preexisting cracks on rockfall fragmentation, two key issues need to be solved. First, a proper numerical tool needs to be selected, which can simulate the whole process of crack propagation, i.e., the continuity to discontinuity of medium, and the large deformation and displacement. Second, the computational efficiency should be sufficiently high because a careful investigation of crack propagation requires dense mesh. Based on those conditions, a parallel two-dimensional Discontinuous Deformation Analysis (2D DDA) on the OpenMP platform is a good choice. DDA was proposed by Shi [35]; it aims to analyze the evolution of blocky systems. Many studies involving DDA have been conducted since it has been proposed [36-43]. DDA has a complete theory about contacts and mechanics involving polygonal blocks, which is clearly suitable for crack propagation study. The virtual joint technique can be adopted to address the propagation of cracks. It refers to the joints that are not present in reality but do exist in models between blocks. The medium can be treated as continuous before cracking; when stress within the medium is great enough to create cracks, the blocks can detach each other through the virtual joints, and the virtual joints then become real joints. It has been introduced into DDA to simulate crack propagation [44-48]. When implementing virtual joints, the cracks extend through joints and the individual blocks keep intact. Apparently, to better describe the propagation of cracks in rockfalls, an intact rock should be meshed into blocks that are small enough. This brings the second issue, i.e., the computational efficiency. The authors have studied OpenMP-based parallel DDA, and the calculation can be significantly accelerated [49-51]. The parallel DDA is adopted in this study to facilitate the simulation of crack propagation in rockfalls.
In this paper, the effect of the preexisting crack in rocks on rockfall impact fragmentation is studied by using parallel DDA based on OpenMP. First, the theory of DDA and the involved methods of virtual joints and parallel techniques are briefly introduced. The implementation of the methods into DDA is also presented. Then, validation examples about flattened and precrack Brazilian disc tests are provided, respectively. After that, the effects of joint-slope angle, joint connectivity rate, and impact velocity on rock crack propagation in rockfall impact fragmentation are discussed in detail. Finally, conclusions are drawn.

\section{Theory of DDA}

Proposed by Dr. Shi [35], DDA has become a widely used tool in simulations involving discrete geological models such as landslides and rockfalls. The basic element in a DDA model is called block, which is an arbitrarily shaped polygon with constant stress and strain. The displacement variables are written into a vector form:

$$
D_{i}=\left(u_{0}, v_{0}, r_{0}, \varepsilon_{x}, \varepsilon_{y}, \gamma_{x y}\right) \text {, }
$$

where $D_{i}$ is the deformation matrix of block $i$ in a blocky system; $u_{0}$ and $v_{0}$ are the $x$ - and $y$-wise displacements at the centroid $\left(x_{0}, y_{0}\right)$, respectively; $r_{0}$ is the rotation of the block $i$; $\varepsilon_{x}$ and $\varepsilon_{y}$ represent the $x$ - and $y$-wise strains of the block, respectively; and $\gamma_{x y}$ is the shear strain of the block $i$. The displacement of a point $(x, y)$ within block $i$ can be calculated by $D_{i}$ using the following equation:

$$
\left(\begin{array}{l}
u \\
v
\end{array}\right)=T_{i}(x, y) \cdot D_{i}
$$

where $T_{i}(x, y)$ denotes displacement transformation matrix at $P(x, y)$, and it is calculated by

$$
T_{i}(x, y)=\left[\begin{array}{cccccc}
1 & 0 & -\left(y-y_{0}\right) & x-x_{0} & 0 & \left(y-y_{0}\right) / 2 \\
0 & 1 & x-x_{0} & 0 & y-y_{0} & \left(x-x_{0}\right) / 2
\end{array}\right] .
$$

The dynamic behavior of a system can be described by

$$
M \ddot{D}+C \dot{D}+K D=F,
$$

where $D, \dot{D}$, and $\ddot{D}$ denote the matrices of displacement, velocity, and acceleration, respectively, and $M, C$, and $K$ represent the matrices of mass, damping, and stiffness, respectively, of a system subject to the forcing matrix $F$. The damping matrix $C$ takes the form of

$$
C=\eta M
$$

where $\eta$ is the viscosity. In this study, the viscosity $\eta$ equals zero and thus no viscous damping is introduced. The energy loss is caused by the friction between blocks because the Mohr-Coulomb yield criterion is adopted to control the block sliding.

Equation (4) is solved by Newmark's $\beta$ and $\gamma$ method, with parameters $\gamma=1.0$ for velocity weighting and $\beta=0.5$ for acceleration weighting: 


$$
\begin{aligned}
& D^{n+1}=D^{n}+\Delta t \dot{D}^{n}+(\Delta t)^{2} \frac{\left[(1-2 \beta) \ddot{D}^{n}+2 \beta \ddot{D}^{n+1}\right]}{2}, \\
& \dot{D}^{n+1}=\dot{D}^{n}+\Delta t\left[(1-\gamma) \ddot{D}^{n}+\gamma \ddot{D}^{n+1}\right],
\end{aligned}
$$

where superscript $n$ denotes the calculation step. Taking $D^{n}=0$ as the displacement at the start of the current calculation step and solving for the acceleration $\ddot{D}^{n+1}$ from equation (6) result in

$$
\ddot{D}^{n+1}=\frac{2}{(\Delta t)^{2}} D^{n+1}-\frac{2}{\Delta t} \dot{D}^{n} .
$$

Substituting equations (8) into (7), the velocities at the end of the current calculation step are obtained as

$$
\dot{D}^{n+1}=\frac{2}{\Delta t} D^{n+1}-\dot{D}^{n}
$$

Substituting equations (8) and (9) into (4) forms the global form

$$
\widetilde{K} D^{n+1}=\widetilde{F},
$$

where $\widetilde{K}$ and $\widetilde{F}$ are generalized stiffness matrix and force matrix, respectively. Assuming that a blocky system contains $n$ blocks, equation (10) can be rewritten as

$$
\left[\begin{array}{cccc}
K_{11} & K_{12} & \cdots & K_{1 n} \\
K_{21} & K_{22} & \cdots & K_{2 n} \\
\vdots & \vdots & \vdots & \vdots \\
K_{n 1} & K_{n 2} & \cdots & K_{n n}
\end{array}\right]\left[\begin{array}{c}
D_{1} \\
D_{2} \\
\vdots \\
D_{n}
\end{array}\right]=\left[\begin{array}{c}
F_{1} \\
F_{2} \\
\vdots \\
F_{n}
\end{array}\right],
$$

where $K_{i j}$ is the stiffness submatrices and $F_{i}$ is the loading submatrices of block $n$.

\section{Parallel DDA with Virtual Joints and Its Verification}

To model rock crack propagation during impact fragmentation in rockfalls, the domain of interest is generally discretized into a large number of triangular blocks using a triangular mesh generation method. Hence, a large-scale blocky system must be involved. To ensure efficiency, the parallel DDA with virtual joints is adopted to solve such problems.

3.1. Parallel DDA with Virtual Joints. The virtual joint in DDA is a general technique to study rock crack propagation, as shown in Figure 1. The essential of modeling rock crack propagation lies in the representation of an intact rock by gluing adjacent blocks through virtual joints and in the representation of the cracking by removing the linkage between the glued blocks. More specifically, the gluing of blocks can be realized by specifying strong strength parameters (friction, cohesion, and tensile strength) for virtual joints; meanwhile, the rock cracking is implemented by converting the virtual joints into real joints (with weak strength parameters). There are thus two kinds of interfaces

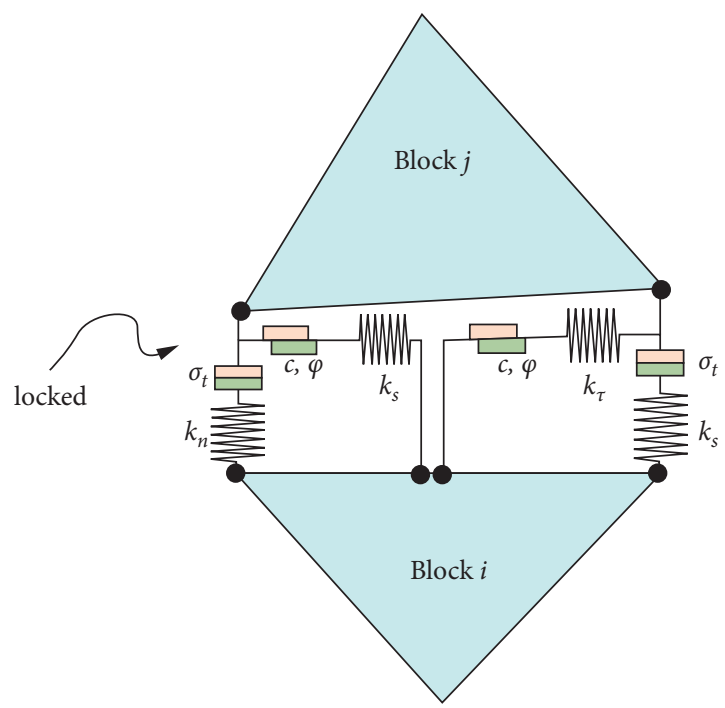

Figure 1: Schematic diagram of virtual joints.

between blocks: virtual and real interfaces. The real interfaces represent the real discontinuities (including the existing joints or fractures, the primary cracks, and the newly propagated cracks) whereas the virtual interfaces indicate the block boundaries that are artificially cut in the continuous domain [45]. The crack propagating paths in an intact rock are predetermined by the virtual joint system, and any crack propagates along the virtual interfaces.

With an aim to simulate continuous rock, a cohesive algorithm is applied to glue the adjacent blocks together through virtual interfaces for preventing their detachment. In DDA, when the contact between two blocks is in a locked contact state, both normal and shear contact springs are applied to prevent normal penetration and relative shear displacement. Once the contact force exceeds the joint strength, the corresponding contact spring is removed, and the contact state is changed. To ensure the bonding between adjacent blocks, the strength parameters of the virtual joints take the same values as those of the rock material. When the failure criterion is satisfied, the bonding between the adjacent blocks fails and the virtual interface becomes a real interface, which results in the crack initiation or propagation occurred at this interface. There are two types of failure: the tensile failure and the shear failure that are, respectively, along the normal and tangential directions. The tensile failure adopts the maximum tensile stress criterion while the shear failure employs the Mohr-Coulomb criterion. The maximum tensile and shear forces are, respectively, computed by

$$
\begin{aligned}
& f_{t, \text { max }}=\sigma_{t} l, \\
& f_{s, \text { max }}=c l+f_{n} \tan \varphi,
\end{aligned}
$$

where $\varphi, c$, and $\sigma_{t}$ are, respectively, the internal friction angle, cohesion, and tensile strength of the rock material; $l$ is the contact length of the virtual joint; and $f_{n}$ is the normal contact force. To determine the failure mode, two ratios $\left(r_{1}\right.$ and $r_{2}$ ) are used and calculated as 


$$
\begin{aligned}
& r_{1}=\frac{f_{n}}{f_{t, \text { max }}}, \\
& r_{2}=\frac{f_{s}}{f_{s, \text { max }}},
\end{aligned}
$$

where $f_{s}$ is the shear contact force. If $r_{1}>1$ or $r_{2}>1$, the tensile failure or the shear failure occurs, leading to crack initiation or propagation along the virtual joint plane. When both $r_{1}$ and $r_{2}$ exceed 1 , their values should be compared further: if $r_{1}>r_{2}$, the tensile failure occurs; otherwise, the shear failure occurs. The flowchart of the cracking judgment process for virtual joints is presented in Figure 2.

Nevertheless, with the incorporation of virtual joints into DDA, the problem of computational ability becomes prominent because the mesh must be very dense to make crack propagation more realistic. In this case, a parallel technique based on OpenMP is adopted to accelerate the simulation. The previous work of [51] is followed in which a parallel framework for 2D DDA was developed and the parallel 2D DDA was applied to study a large-scale rockslide (containing numerous blocks) induced by earthquake. The parallelization for 2D DDA is briefly introduced here, and the interested readers are suggested to refer to [51].

A 2D DDA program can be regarded as an assembly of subroutines, and each of them has certain purposes and tasks. The main subroutines are contact detection, matrix assembly, equation solver, and contact post judgment. Those subroutines can consume as much as $96 \%$ of the total calculation time according to our previous research [51]. Therefore, by parallelizing the major subroutines, computational efficiency can be significantly improved, and the modeling of crack propagation will be easier. In this parallel strategy, independent tasks, for example, contact detection for every pair of blocks, are distributed to several threads that are forked by a master thread. These slave threads are then executed separately. However, for the tasks with data dependency or data race, some additional measures have to be implemented in advance, such as modifications of code structure or using atomic operation. Based on the previous work, the subroutine to complete the cracking judgment process for virtual joints is also executed in parallel. This is implemented by placing the compiler direction "\#pragma omp parallel for" before the for loop that iterates every virtual joint, as shown in the upper shaded box in Figure 2.

3.2. Verification for Accuracy and Efficiency. The mechanical parameters such as tensile strength and fracture toughness of rock material can be determined by using the flattened Brazilian disc test. To verify the accuracy of the parallel DDA, the splitting process of the flattened Brazilian disc test is numerically studied. The Brazilian disc has a diameter of $100 \mathrm{~mm}$ and flats at each end with a central angle of $10^{\circ}$ according to [52]. Three numerical models with different block quantities $(2045,4107,6081)$ are constructed, as shown in Figure 3. The disc is placed between two platens each with a thickness of $20 \mathrm{~mm}$. The top platen serves as the loading end and the bottom platen is fixed. The mechanical properties for blocks to form the flattened Brazilian disc are the density of $2050 \mathrm{~kg} / \mathrm{m}^{3}$, Young's modulus of $10.53 \mathrm{GPa}$, and Poisson's ratio of 0.12 .

The strength parameters for virtual joints and real joints in the calculation are listed in Table 1. In the loading process, a time-dependent displacement constraint is applied at the loading platen at a loading rate of $2 \mathrm{~mm} / \mathrm{s}$. The calculation parameters in DDA are normal spring stiffness $k_{n}$ of $10 \mathrm{GPa}$, maximum time step size $\Delta t$ of $1 \times 10^{-7} \mathrm{~s}$, and maximum displacement ratio of $1 \times 10^{-4}$. In the simulation, gravity is not considered.

Under the diametrical compression, the crack initiation and propagation are reproduced. The cracks first initiate from the loading regions under the top platen and above the bottom platen. With the increasing loading, the cracks propagate along the vertical middle line, and finally, they coalesce to form a penetrative crack, dividing the specimen into two parts. The splitting process is similar to that in the experiment. The final splitting failure for the three numerical models is shown in Figure 4, compared with the experimental result [52]. The simulated results are in good agreement with the experiment one, suggesting the accuracy of the parallel DDA with virtual joints. In addition, a large number of microcracks appear in the top and bottom ends of the Brazilian disc, which may be attributed to the excessive stiffness of the platens.

On the other hand, the efficiency of the parallel DDA to analyze the rock crack propagation is investigated. The speedup ratio, defined as the ratio between serial and parallel CPU times, is calculated. The CPU times and the calculated speedup ratios for the three numerical models are compared in Figure 5. One can observe that the parallel DDA has approximately 5 times enhanced efficiency with 6 OpenMP threads used, compared with the serial computing.

In addition, the crack propagation of the precracked Brazilian disc (with a diameter of $100 \mathrm{~mm}$ ) is also numerically studied. The single crack in the middle part of the disc has a length of $25 \mathrm{~mm}$, and different values of the crack inclination $\left(30^{\circ}, 45^{\circ}, 60^{\circ}, 75^{\circ}\right)$ are considered. By making a compromise between efficiency and accuracy, the domain of interest is discretized into around 4000 smaller blocks for each case [53]. The numerical model with a crack inclination of $45^{\circ}$ is depicted in Figure 6.

The same mechanical properties and calculation parameters in DDA are adopted. The simulated final failure for the precracked Brazilian disc with different crack inclination angles is presented in Figure 7, compared with the experimental results [54]. It can be seen that both the crack propagation path and the fracture feature obtained by the parallel DDA accord well with the experiment results.

\section{Study on Crack Propagation and Fracture Behaviors in Impact Fragmentation}

In this section, the crack propagation of jointed rock mass under impact loads will be explored. The disc models of single jointed rock mass under different conditions are numerically analyzed. The fracturing behaviors during impact fragmentation as well as the effects of different factors on the impact fragmentation are studied. 


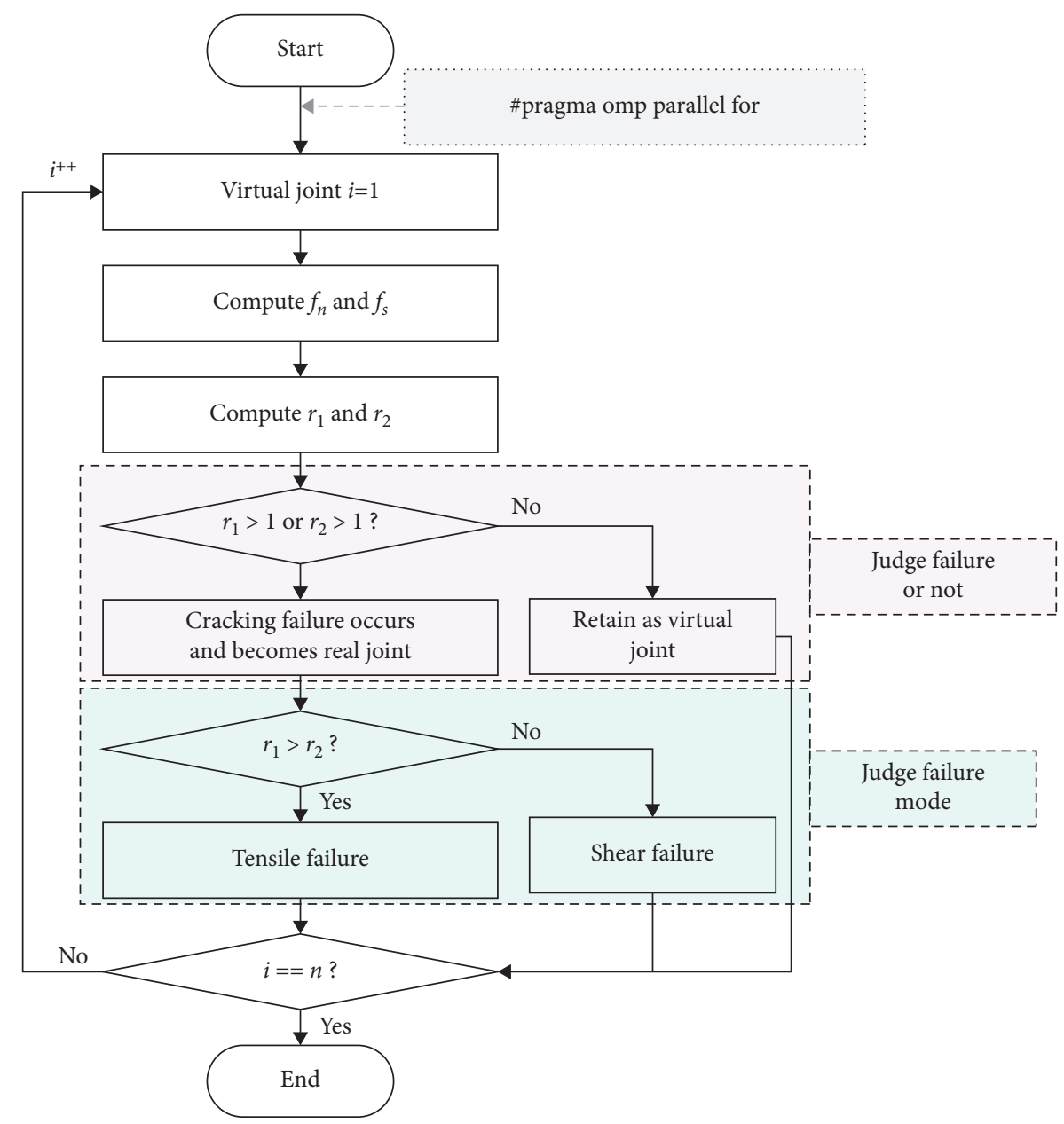

FIgURE 2: Flowchart of the cracking judgment process for virtual joints.

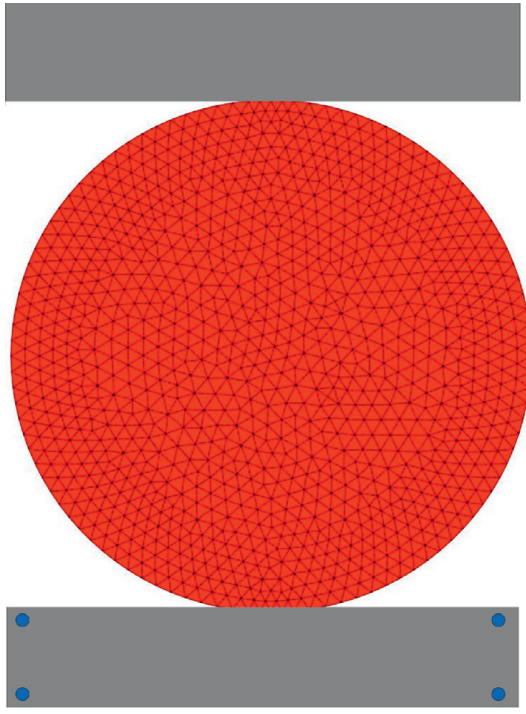

(a)

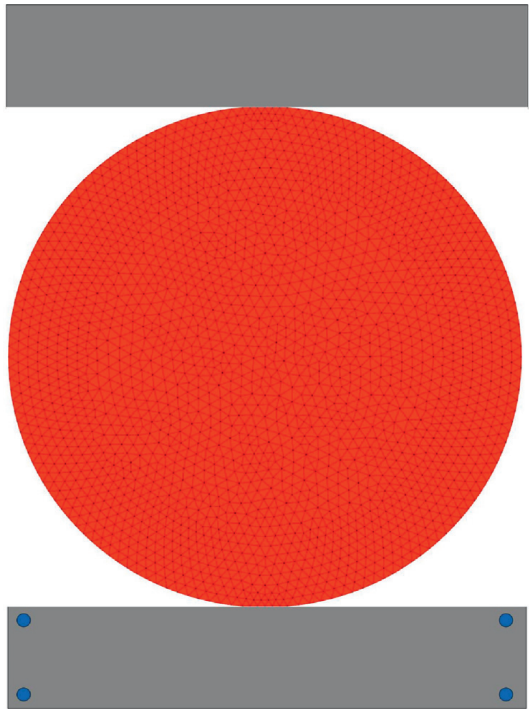

(b)

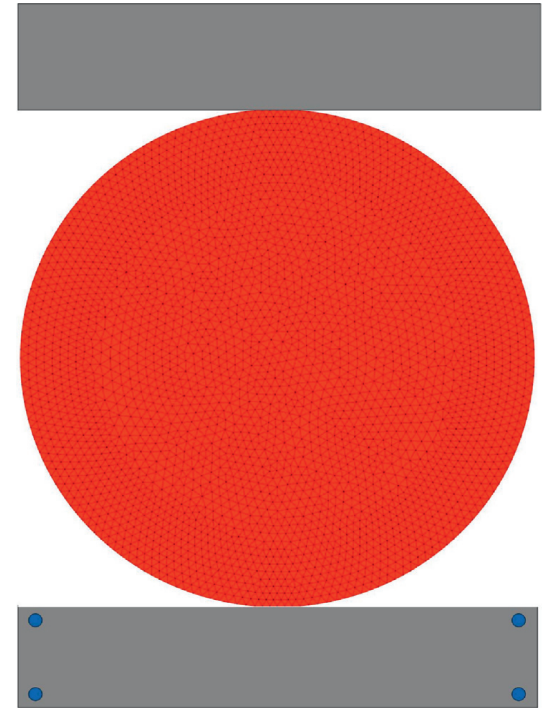

(c)

FIGURE 3: Three numerical models with different block quantities for the flattened Brazilian disc test. (a) 2045 blocks. (b) 4107 blocks. (c) 6081 blocks. 
TABLE 1: Strength parameters for virtual joints and real joints when DDA simulating the flattened Brazilian disc test.

\begin{tabular}{lcc}
\hline & Virtual joints & Real joints \\
\hline Friction angle $\varphi\left({ }^{\circ}\right)$ & 38.5 & 20 \\
Cohesion $c(\mathrm{MPa})$ & 8.29 & 1 \\
Tensile strength $\sigma_{t}(\mathrm{MPa})$ & 7.86 & $1 \times 10^{-5}$ \\
\hline
\end{tabular}

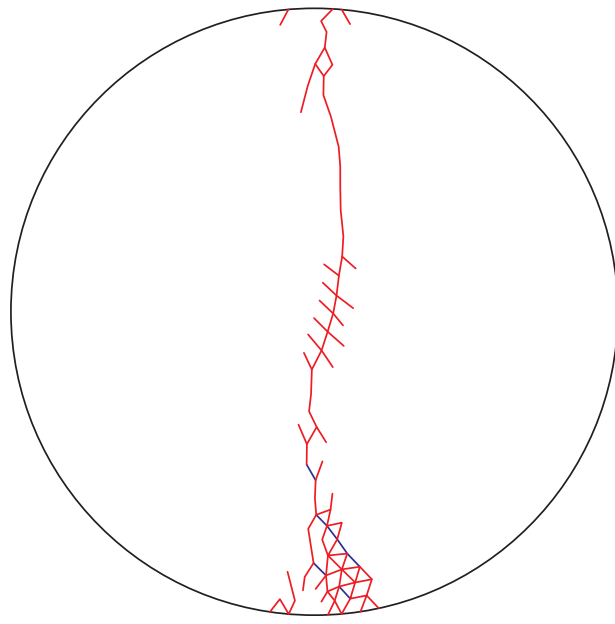

(a)

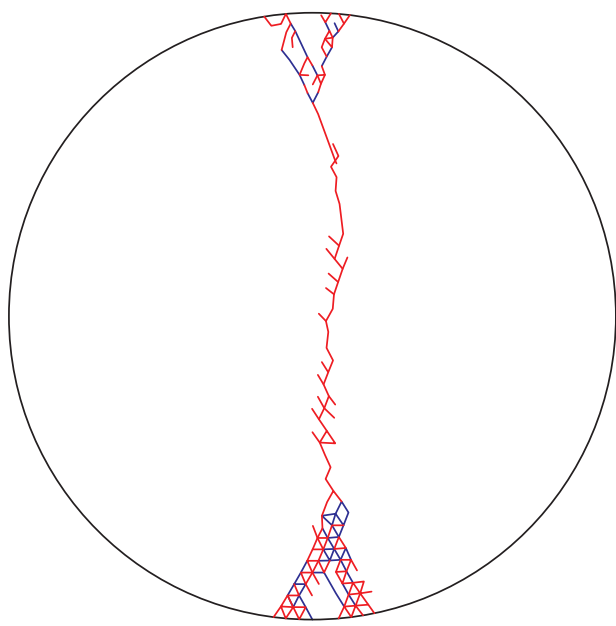

(c)

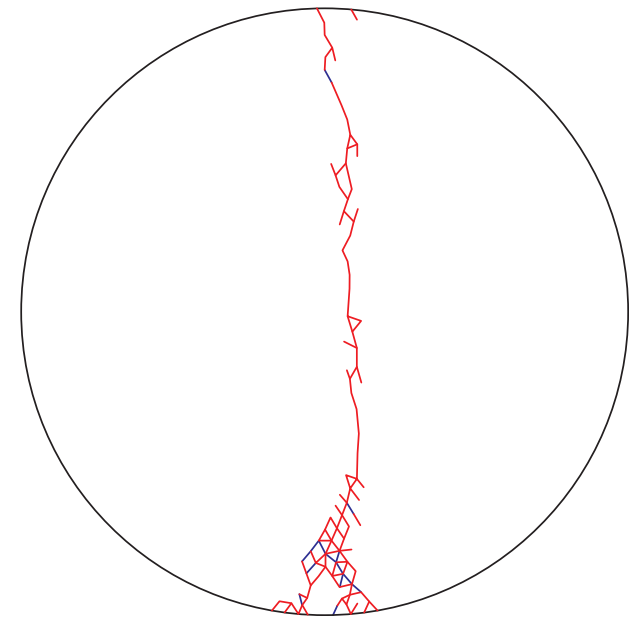

(b)

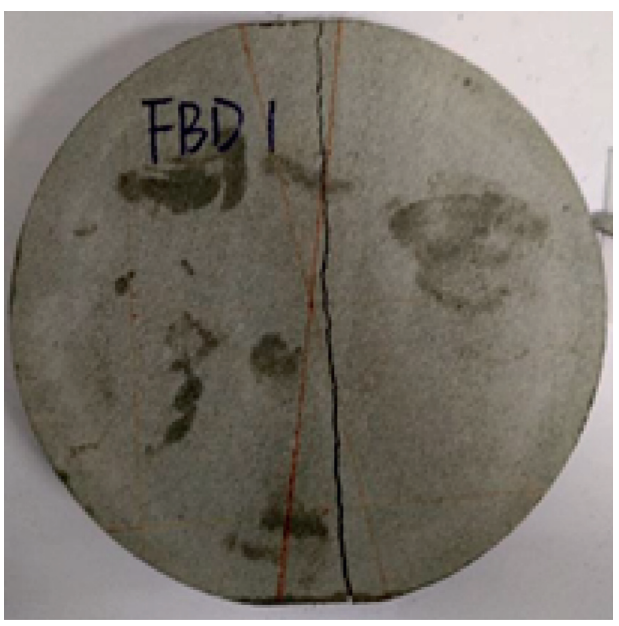

(d)

FIgURE 4: The final splitting failure for the three numerical models with different block quantities of blocks, compared with the experiment result [52]. (a) 2045 blocks. (b) 4107 blocks. (c) 6081 blocks. (d) experiment result.

The model for rockfall impact fragmentation comprises a rectangular collision plate $(100 \mathrm{~mm} \times 20 \mathrm{~mm})$ and a disc (with a diameter of $100 \mathrm{~mm}$ ) formed by numerous smaller blocks (around $5500 \sim 5600$ ). The collision plate is placed at the bottom and keeps fixed in the whole simulation. The disc vertically impacts the collision plate. The disc contains a single crack with a width of $0.4 \mathrm{~mm}$ in the middle part. Different joint-slope angles $\theta\left(0^{\circ}, 15^{\circ}, 30^{\circ}, 45^{\circ}, 60^{\circ}, 75^{\circ}\right.$, and $\left.90^{\circ}\right)$ as well as different joint connectivity rates $\gamma(0.25,0.50$, and 0.75 ) are considered. A representative numerical model is shown in Figure 8. To save time, the free fall process is not calculated, and instead, the disc with an initial velocity of $v_{0}$ impacts the collision plate as the simulation begins. The same mechanical properties listed in Section 3 are employed for both blocks and joints. The calculation parameters in DDA for dynamic simulation are set as normal spring stiffness $k_{n}$ of $0.35 \mathrm{GPa}$, maximum time step size $\Delta t$ of $1 \times 10^{-7} \mathrm{~s}$, and maximum displacement ratio of $1 \times 10^{-4}$. In the simulation, gravity is considered.

Considering different values of the joint-slope angle $\theta$, the joint connectivity rate $\gamma$, and the initial impact velocity $v_{0}$, various cases (as listed in Table 2) are studied.

4.1. Analysis of Fracture Behaviors in Impact Fragmentation. Figure 9(a) shows the failure states for the impact fragmentation modeling when different joint-slope angles $\theta\left(0^{\circ}\right.$, $30^{\circ}, 45^{\circ}, 60^{\circ}, 90^{\circ}$ ) are considered. In the different cases, the 


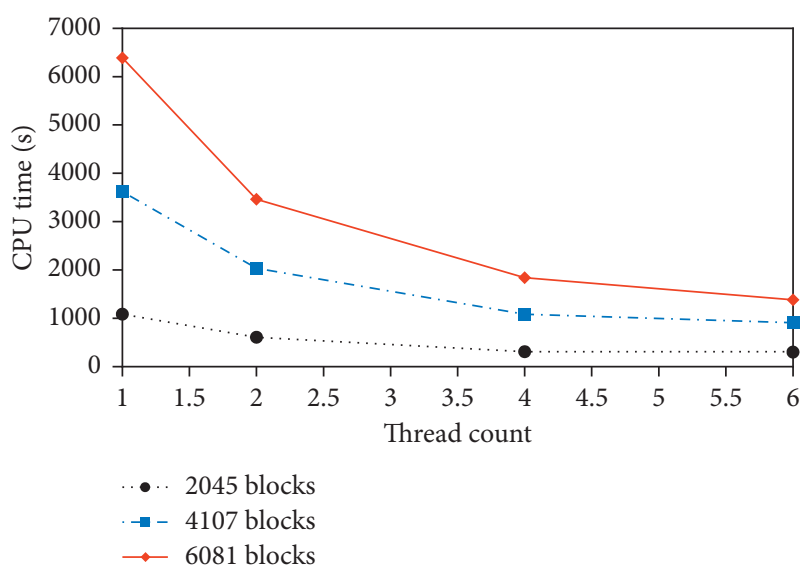

(a)

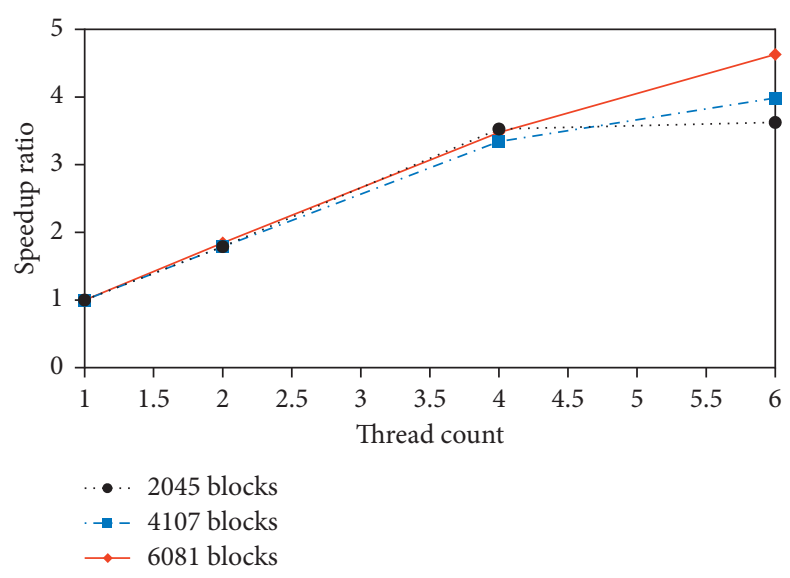

(b)

FIgURE 5: The CPU times and the calculated speedup ratios for the three numerical models of the flattened Brazilian disc test. (a) CPU times. (b) Calculated speedup ratios.

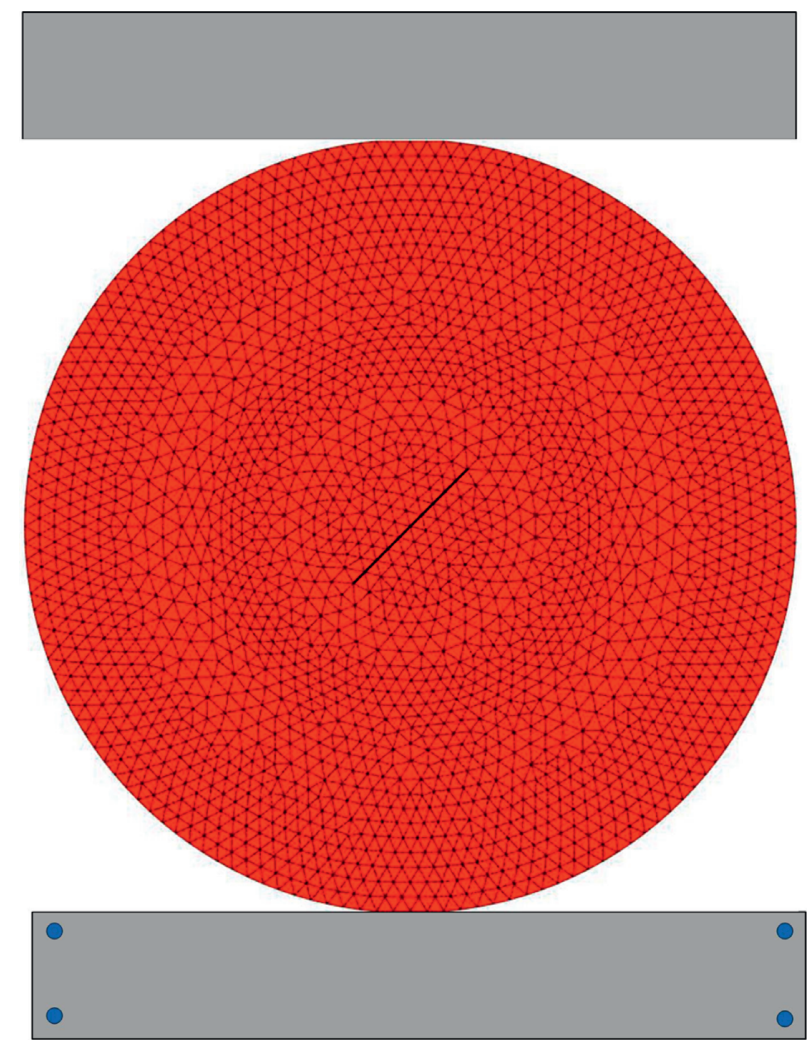

FIgURE 6: Numerical model of the precracked Brazilian disc with $45^{\circ}$ crack.

joint connectivity rate $\gamma$ is 0.25 , and the initial impact velocity $v_{0}$ is $3.5 \mathrm{~m} / \mathrm{s}$. When $\theta=0^{\circ}$, the fragmentation first occurs at the region near the impacting point, and individual blocks are cut out by the newly appeared cracks. The cracks then initiate from the middle of the joint and propagate radially toward the impact point and the top end of the specimen, and finally, they coalesce to form a penetrative crack. When $\theta=45^{\circ}$, two wing cracks perpendicular to the joint are first formed at the two ends of the prefabricated joint and gradually propagate toward the impact point and the top end of the specimen, and finally, two macrocracks are formed. When $\theta=30^{\circ}$ or $60^{\circ}$, the crack initiation and propagation are similar to those in the case of $\theta=45^{\circ}$. When $\theta=90^{\circ}$, the stress wave is affected when it propagates from the impact point to the lower end of the joint, and it repeatedly oscillates between the impact point and the lower 
a1

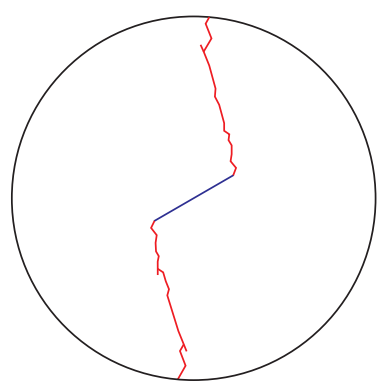

b1

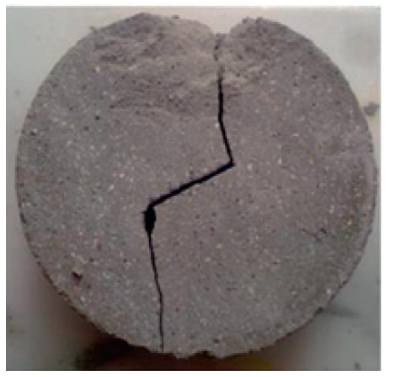

a2

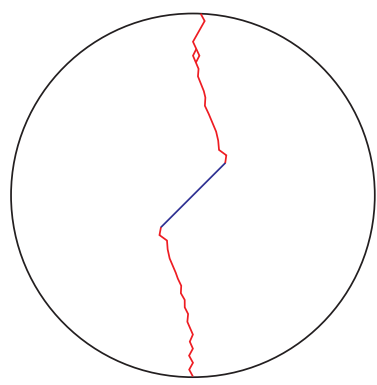

(a)

b2

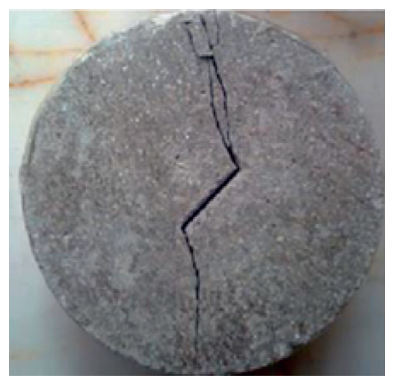

a3

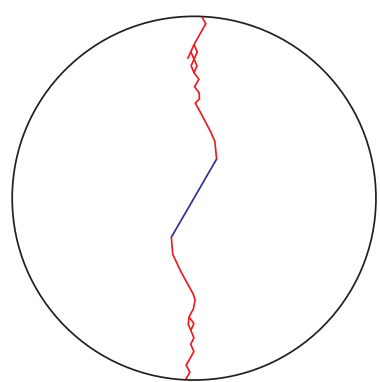

b3

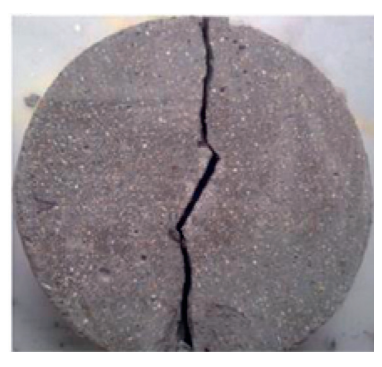

a4

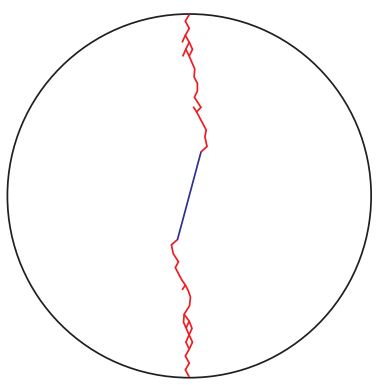

b4

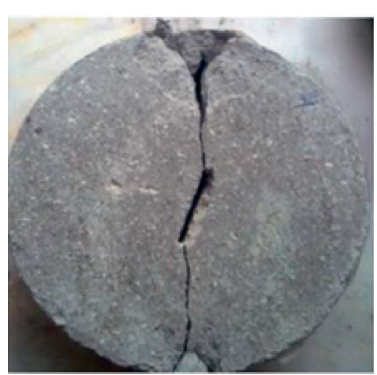

(b)

FIgURE 7: Comparison of the crack propagation paths from (a) the simulated and (b) the experimental results [54] for the precracked Brazilian disc with different crack inclination angles. a1 and b1 are 30 degrees, a2 and b2 are 45 degrees, a 3 and b3 are 60 degrees, and a 4 and b4 are 75 degrees.

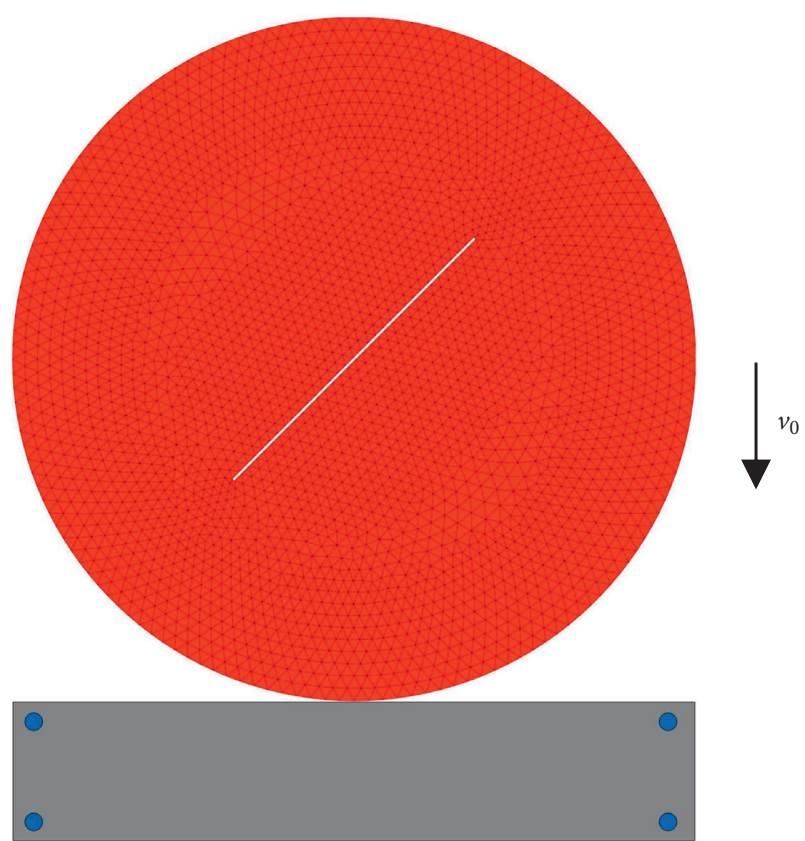

Figure 8: A representative numerical model $\left(\theta=45^{\circ}\right.$ and $\left.\gamma=0.50\right)$ of rockfall impact fragmentation simulation.

end of the joint, resulting in a large amount of debris near the impact point. At the same time, the cracks propagate from the upper and lower ends of the joint toward the ends of the specimen in the vertical direction, finally leading to the
TABle 2: Different values of the joint-slope angle $\theta$, the joint connectivity rate $\gamma$, and the initial impact velocity $v_{0}$ for different cases.

\begin{tabular}{lccccccc}
\hline Case no. & $\theta\left({ }^{\circ}\right)$ & $\gamma$ & $v_{0}(\mathrm{~m} / \mathrm{s})$ & Case no. & $\theta\left({ }^{\circ}\right)$ & $\gamma$ & $v_{0}(\mathrm{~m} / \mathrm{s})$ \\
\hline 1 & 0 & 0.25 & 3.5 & 8 & 45 & 0.25 & 3.5 \\
2 & 15 & 0.25 & 3.5 & 9 & 45 & 0.50 & 3.5 \\
3 & 30 & 0.25 & 3.5 & 10 & 45 & 0.75 & 3.5 \\
4 & 45 & 0.25 & 3.5 & 11 & 45 & 0.25 & 3.0 \\
5 & 60 & 0.25 & 3.5 & 12 & 45 & 0.25 & 3.5 \\
6 & 75 & 0.25 & 3.5 & 13 & 45 & 0.25 & 4.0 \\
7 & 90 & 0.25 & 3.5 & 14 & 45 & 0.25 & 5.0 \\
& & & & 15 & 45 & 0.25 & 6.0 \\
\hline
\end{tabular}

penetration failure of the specimen. By making a comparison between the simulated failure patterns presented in Figure 9(a) and the experiment results [55] shown in Figure 9(b), the fracturing behaviors are quite consistent.

In addition, the crack mechanism in impact fragmentation is clarified based on the calculation results in Case 4 $\left(\theta=45^{\circ}, \gamma=0.25\right.$, and $\left.v_{0}=3.5 \mathrm{~m} / \mathrm{s}\right)$. The penetrative crack formed in the specimen is the resultant failure mode of the stress distribution. In the simulation, the maximum principal stresses at different measurement points are recorded, as presented in Figure 10. The tensile stress is positive while the compressive stress is negative. It can be observed that after the specimen impacts the collision board, only the part near the impact point presents relatively large compressive stress whereas the tensile stress dominates the other parts. Measurement point $A$ near the impact point shows gradually 


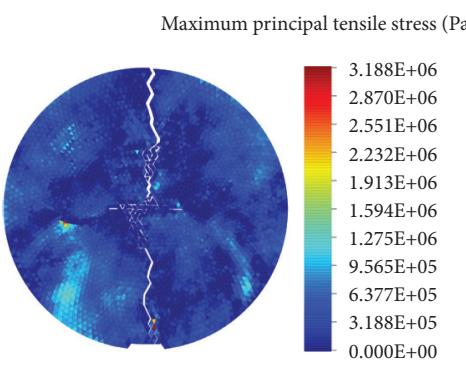

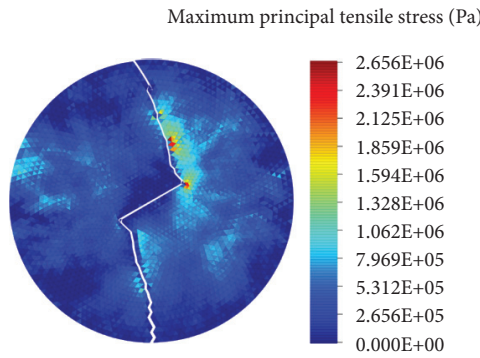

a3

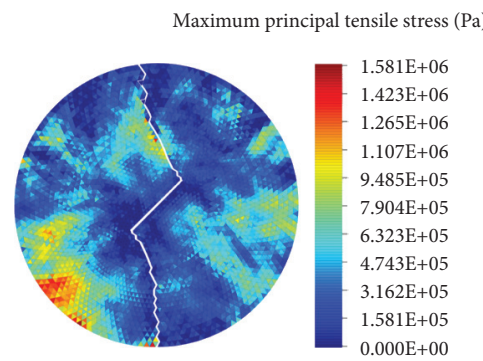

a4

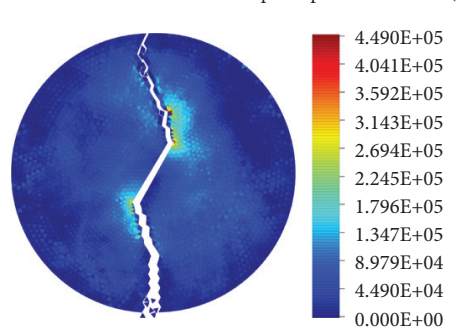

b1

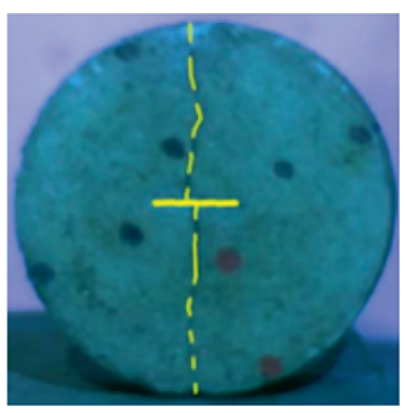

b4

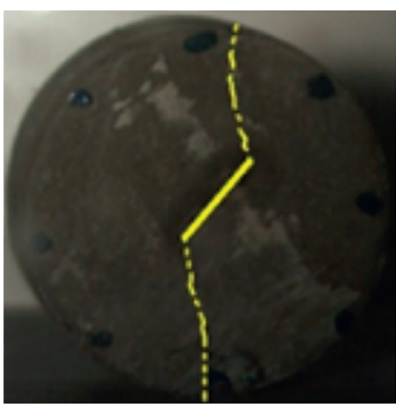

(a)

a5

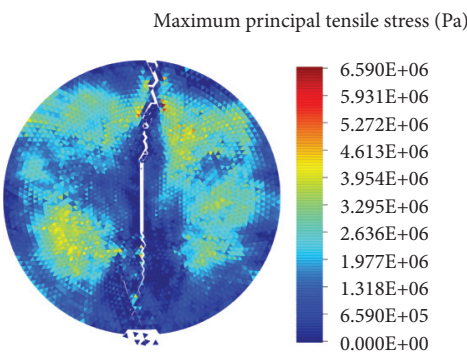

b2
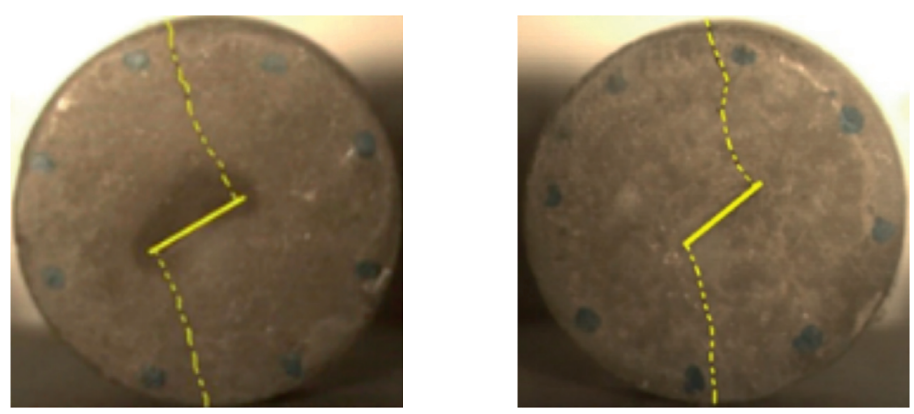

b5

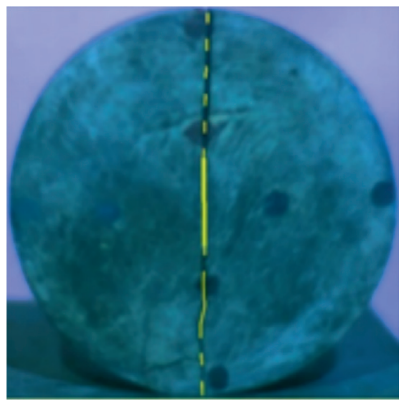

(b)

FIGURE 9: Comparison of failure states for the impact fragmentation modeling obtained from (a) the parallel DDA and (b) the experiment when the different joint-slope angles are considered $\left(\gamma=0.25\right.$ and $\left.v_{0}=3.5 \mathrm{~m} / \mathrm{s}\right)$. a1 and b1 are 0 degrees, a 2 and b2 are 30 degrees, a 3 and b3 are 45 degrees, a 4 and b4 are 60 degrees, and a5 and b5 are 90 degrees.

decreasing compressive stress after reaching the maximum compressive stress peak, suggesting the occurrence of the plastic deformation inside the specimen. The measurement points $(B, C$, and $D)$ placed along the vertical direction of the specimen successively attain the peak values from the bottom to the top. At about $265 \mu$ s, the measurement point $E$ near the lower end of the joint first gets the peak stress and then rapidly decreases, which enables the stress redistribution. At about $285 \mu \mathrm{s}$, the measurement point $F$ near the upper end of the joint also reaches the peak stress. All the peak stresses of these two measurement points near the joint exceed the tensile strength of the specimen, and thus the tensile failure occurs. The peak values of stresses at the measurement points $G$ and $H$ placed near the middle of the joint are small so that the failure will not occur in the middle of the joint. 

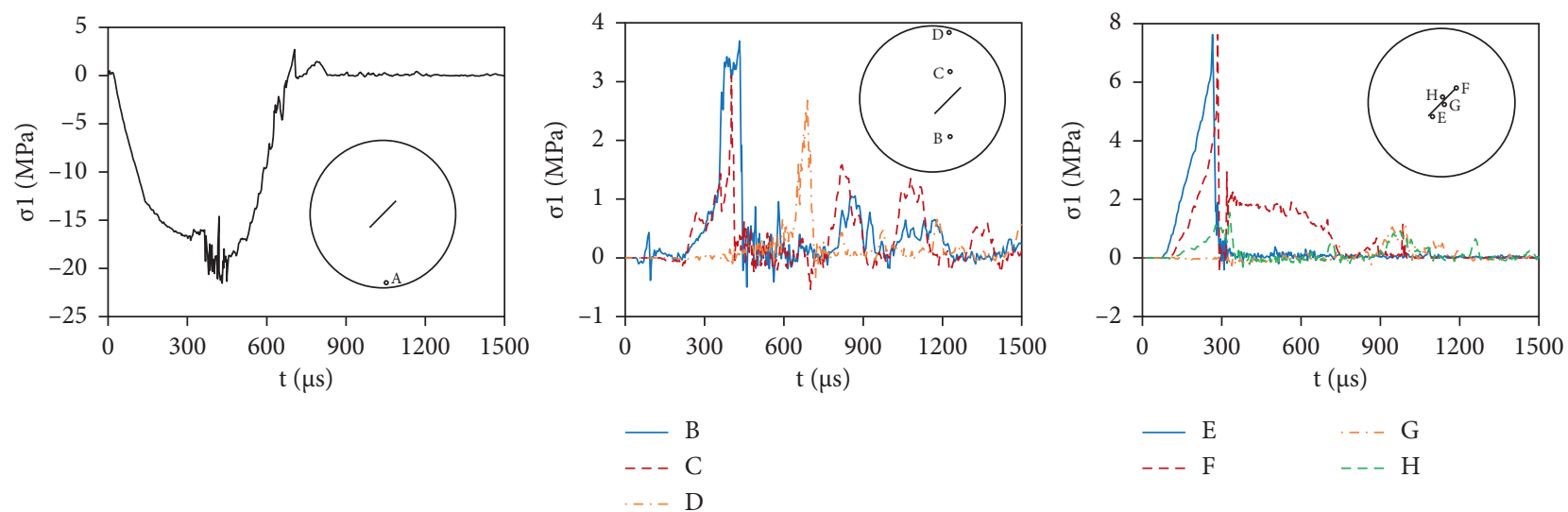

FIGURE 10: Time histories of the maximum principal stresses at different measurement points in Case $4\left(\theta=45^{\circ}, \gamma=0.25\right.$, and $\left.v_{0}=3.5 \mathrm{~m} / \mathrm{s}\right)$.

Since the tensile strength of the rock material is much smaller than its compressive strength, the tensile failure typically occurs during the impact failure process. In order to reflect the failure of the specimen more clearly, the simulated maximum principal stress contours are plotted in Figure 11. One can also observe that relatively large compressive stresses appear in the area near the impact point of the specimen, but the compressive stress is only distributed in a small range near the impact point.

At about $300 \mu s$, the maximum tensile stress exceeds the tensile strength of the specimen, causing the virtual joints of these blocks near the two ends of the preset joint to fail, and the cracks are thus initiated. At about $500 \mu s$, the lower crack propagates toward the impact point, and the upper crack propagates toward the top end of the specimen. At about $800 \mu \mathrm{s}$, the cracks coalesce to form a penetrative crack, and the specimen is completely penetrated and destroyed. The failure of the specimen can be divided into three stages, namely, crack initiation, crack propagation, and crack penetration.

In addition, the simulated maximum principal stress contours in Case $1\left(\theta=0^{\circ}, \gamma=0.25\right.$, and $\left.v_{0}=3.5 \mathrm{~m} / \mathrm{s}\right)$ and Case $7\left(\theta=90^{\circ}, \gamma=0.25\right.$, and $\left.v_{0}=3.5 \mathrm{~m} / \mathrm{s}\right)$ are shown in Figure 12. In Case 1, many microcracks appear in the periphery of the preset joint at about $400 \mu \mathrm{s}$, and macrocracks sprout upward in the middle of the joint. The crack propagation gradually stagnates for a while. At about $900 \mu \mathrm{s}$, the radial cracks continue to propagate toward the impact point or the top end of the specimen. At $1400 \mu \mathrm{s}$, the upper cracks expand to the top end and the lower cracks expand to the impact point, causing the specimen to be completely penetrated and destroyed. In Case 7 , at about $300 \mu \mathrm{s}$, the largest maximum principal stresses at the lower and upper ends of the joint, where the cracks initiate and propagate. At about $400 \mu \mathrm{s}$, the radial cracks continue to expand; due to the collision between the specimen and the collision board, stress superimposition is generated at the impact point and the lower end of the joint, resulting in fragmentation near the impact point of the specimen. At about $1200 \mu \mathrm{s}$, the cracks coalesce to form a penetrative crack, and the specimen is completely penetrated and destroyed.
4.2. Effect of Joint-Slope Angles. To study the effect of the joint-slope angle on the impact fragmentation, seven cases (Case 1-Case 7) with different joint-slope angles $\left(\theta=0^{\circ}, 15^{\circ}\right.$, $30^{\circ}, 45^{\circ}, 60^{\circ}, 75^{\circ}$, and $90^{\circ}$ ) are considered. Some discussions have been conducted in Section 4.1. The cumulative number of cracks generated inside the specimen can reflect the internal damage: the more cracks in the specimen, the more serious the internal damage it suffers. Figure 13 shows the comparison of the cumulative crack number at about $1800 \mu \mathrm{s}$. It can be seen that the number of accumulated cracks in the specimen increases continuously in the range of $0^{\circ} \sim 30^{\circ}$ and reaches the maximum when the joint-slope angle $\theta$ is set to $30^{\circ} \sim 45^{\circ}$. After that, the number of accumulated cracks decreases with an increase of the joint-slope angle $\theta$. This suggests that the internal damage of the specimen after impacting the collision plate is relatively large in the range of $30^{\circ} \sim 45^{\circ}$.

Figure 14 shows the comparison of the incremental crack number over time when different joint-slope angles are considered. The largest incremental number of cracks occurs at $150 \mu \mathrm{s} \sim 300 \mu \mathrm{s}$ for the specimens with the joint-slope angles of $0^{\circ}$ and $15^{\circ}$, it occurs at $300 \mu \mathrm{s} \sim 450 \mu$ s for the specimens with the joint-slope angles of $30^{\circ}, 45^{\circ}$, and $60^{\circ}$, and it occurs at $450 \mu \mathrm{s} \sim 600 \mu \mathrm{s}$ for the specimens with the joint-slope angles of $70^{\circ}$ and $90^{\circ}$. One can conclude that, with the decrease of the joint-slope angle, the largest incremental number of cracks occurs earlier. Possibly because when the joint-slope angle is smaller, after being reflected by the joint surface, the stress wave is superimposed at the middle or the end of the joint to exceed the tensile strength, thereby initiating cracks and making the incremental number of cracks earlier reach the peak. When the joint-slope angle equals $90^{\circ}$, the joint will just slightly hinder the stress wave from propagating upwards and most of the stress wave will reflect downwards after reaching the top end of the specimen. Therefore, the incremental number of cracks will reach the peak later.

4.3. Effect of the Joint Connectivity Rate. To study the effect of the joint connectivity rate on the impact fragmentation, three cases (Case 8-Case 10) with different joint connectivity 


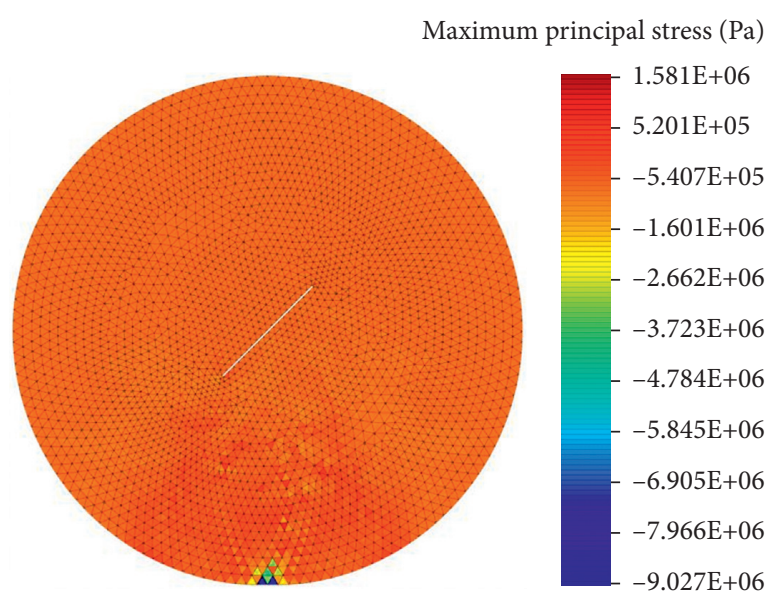

(a)

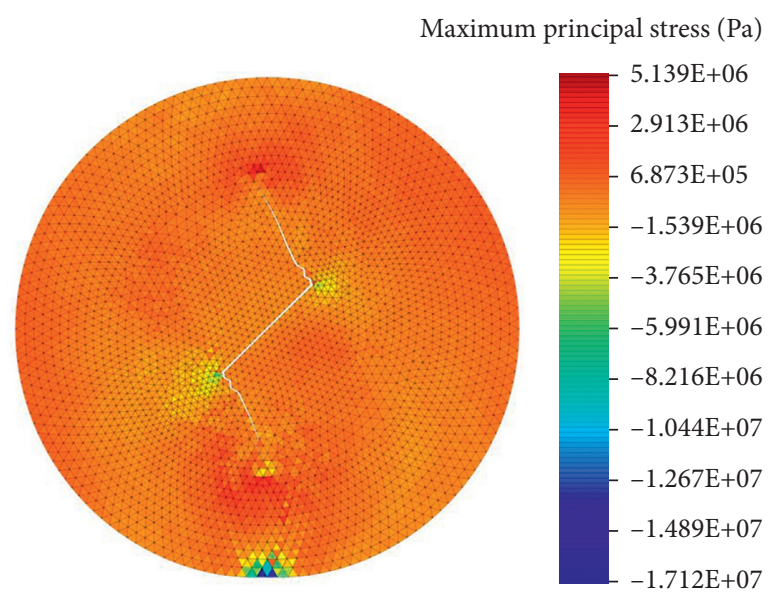

(c)

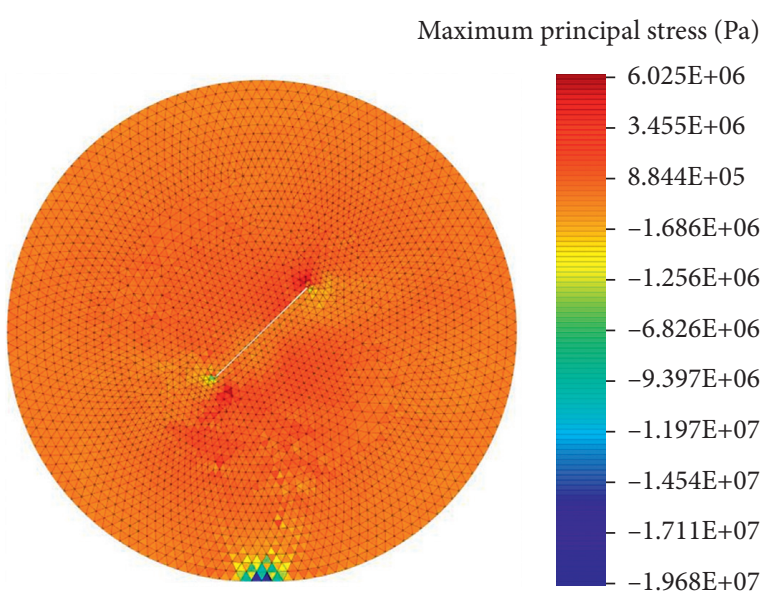

(b)

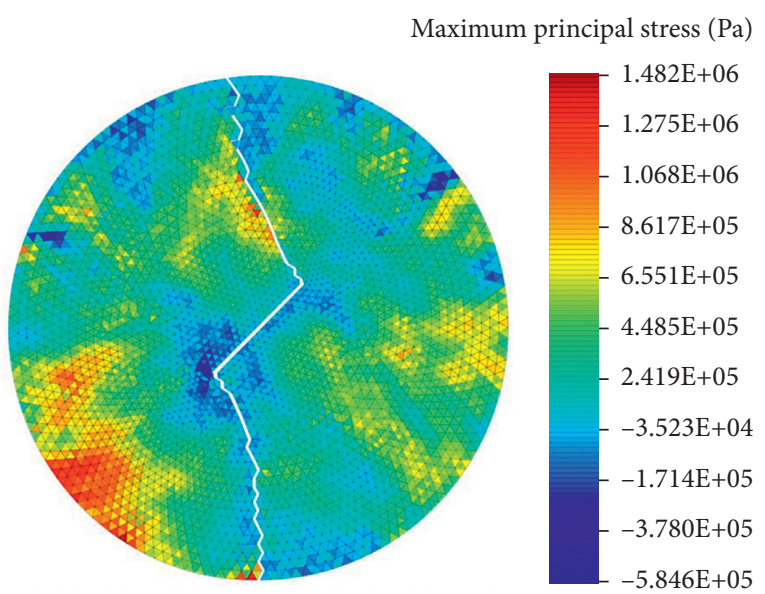

(d)

FIGURE 11: The simulated maximum principal stress contours in Case $4\left(\theta=45^{\circ}, \gamma=0.25\right.$, and $\left.v_{0}=3.5 \mathrm{~m} / \mathrm{s}\right)$. (a) $100 \mu \mathrm{s}$, (b) $300 \mu \mathrm{s}$, (c) $500 \mu \mathrm{s}$, and (d) $800 \mu \mathrm{s}$.

rates $(\gamma=0.25,0.50,0.75)$ are considered. Figure 15 shows the simulated maximum principal stress contours in Case 8 $(\gamma=0.25)$ and Case $10(\gamma=0.75)$.

When the joint connectivity rate is smaller, the smaller damage of the specimen appears. This is because when its length is shorter, the joint shows less influence on the upward propagation of the stress wave. When the joint length is infinitely small, the specimen can be regarded as an intact rock mass without joints. The specimen damage increases with an increase in the joint connectivity rate. It can be seen from Figure 15(b) that the initial cracks appear at the upper position of the lower end of the preset joint, and the stress concentrates at the lower edge of the joint surface.

Figure 16 shows that, with the increasing joint connectivity rate, the cumulative crack number grows, leading to greater internal damage of the specimen. This result further confirms the analysis above. For the specimens with the joint connectivity rates of 0.25 and 0.50 , the growth of the cumulative crack number is slower, and the incremental crack number (as shown in Figure 17) reaches the peak at about $450 \mu \mathrm{s}$; after $1200 \mu \mathrm{s}$, the crack propagation basically terminates. When the joint connectivity rate is 0.75 , the joint has a greater influence on the stress wave. The cumulative number of cracks in the specimen increases sharply, reaching the peak value at $600 \mu \mathrm{s}$. After $1500 \mu \mathrm{s}$, the crack propagation basically terminates. At $1800 \mu \mathrm{s}$, the cumulative crack number of the specimen with the joint connectivity rate of 0.75 is 3.05 and 5.06 times that with the joint connectivity rate of 0.50 and 0.25 , respectively. Therefore, the greater the joint connectivity rate, the greater the damage to the specimen.

4.4. Effect of Impact Velocity. To study the effect of the jointslope angle on the impact fragmentation, five cases (Case 11-Case 15) with different impact velocities $\left(v_{0}=3.0 \mathrm{~m} / \mathrm{s}, 3.5 \mathrm{~m} / \mathrm{s}, 4.0 \mathrm{~m} / \mathrm{s}, 5.0 \mathrm{~m} / \mathrm{s}, 6.0 \mathrm{~m} / \mathrm{s}\right)$ are considered.

Figure 18 shows the simulated maximum principal stress contours in Case $11\left(v_{0}=3.0 \mathrm{~m} / \mathrm{s}\right)$, while Figure 19 shows those results in Case $14\left(v_{0}=5.0 \mathrm{~m} / \mathrm{s}\right)$. When the impact velocity is smaller, the damage to the specimen is lower. As shown in Figure 18, the initial crack stops after extending for a certain distance, and the energy is completely consumed in the process of crack propagation, making the cracks unable to penetrate the specimen. When the specimen rebounds 
(a1)

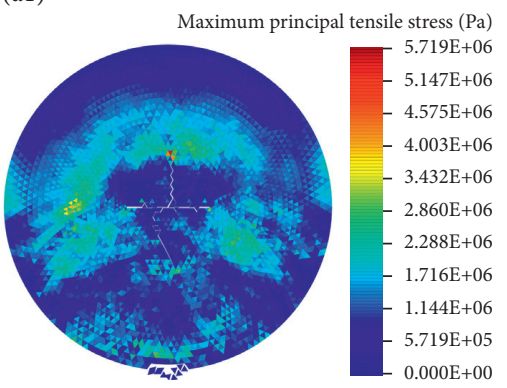

(b1)

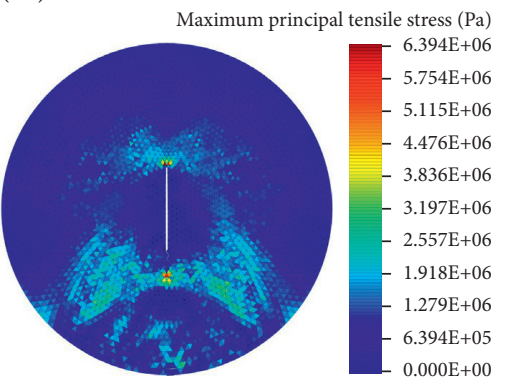

(a2)

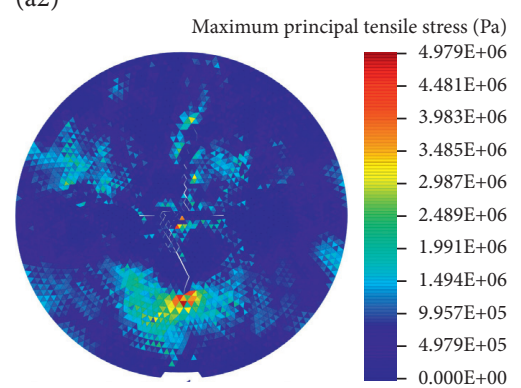

(a)

(b2)

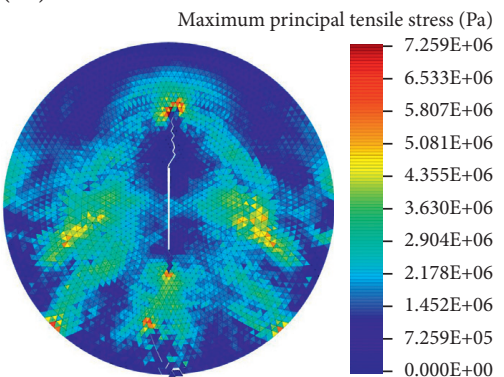

(a3)

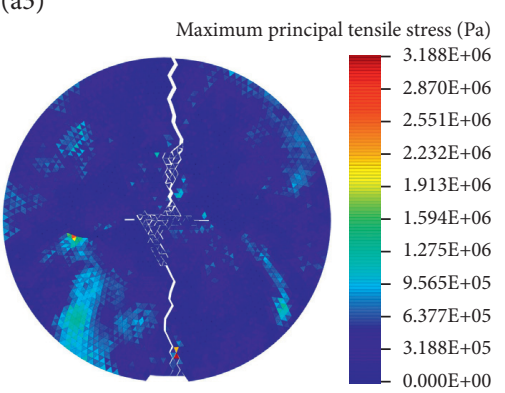

(b3)

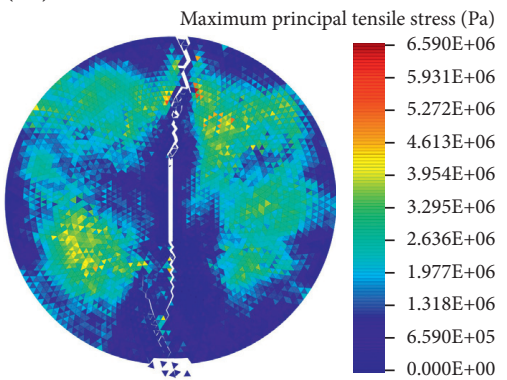

(b)

Figure 12: The simulated maximum principal tensile stress contours in (a) Case 1 and (b) Case $7\left(\gamma=0.25\right.$ and $v_{0}=3.5 \mathrm{~m} / \mathrm{s}$ ). a1 is $400 \mu \mathrm{s}$, a2 is $900 \mu \mathrm{s}, \mathrm{a} 3$ is $1400 \mu \mathrm{s}, \mathrm{b} 1$ is $300 \mu \mathrm{s}, \mathrm{b} 2$ is $400 \mu \mathrm{s}$, and b3 is $1200 \mu \mathrm{s}$.

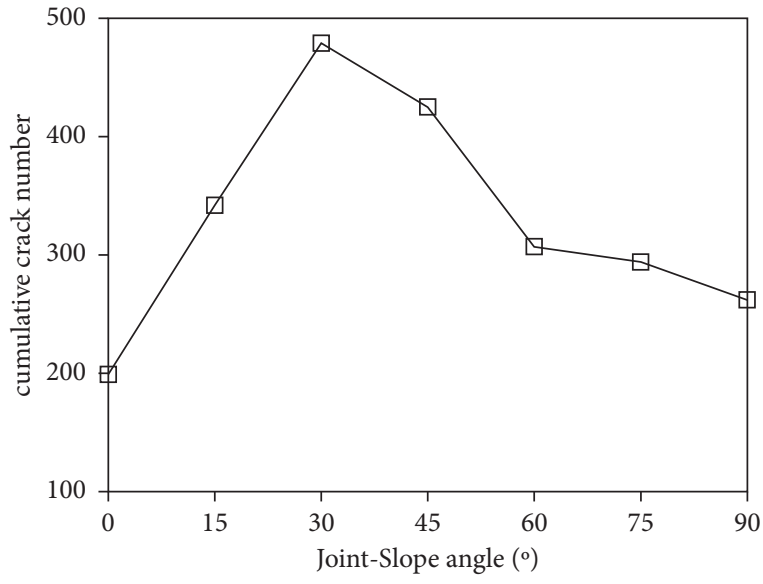

FIGURE 13: Comparison of the cumulative crack number at about $1800 \mu$ s when different joint-slope angles are considered.

upwards, the cracks shrink and become microcracks. As the impact velocity increases, the peak value of the stress also increases. As shown in Figure 19, affected by the impact stress wave, the specimen forms a high-stress zone at the joint end. The wing cracks are first generated at the joint ends, and then, secondary cracks also initiate at the joint ends. Specimen debris appears near the impact point after the collision. As the impact velocity increases, the specimen is more smashed.

Figure 20 compares the cumulative number of cracks in the specimen under different impact velocities. It can be seen

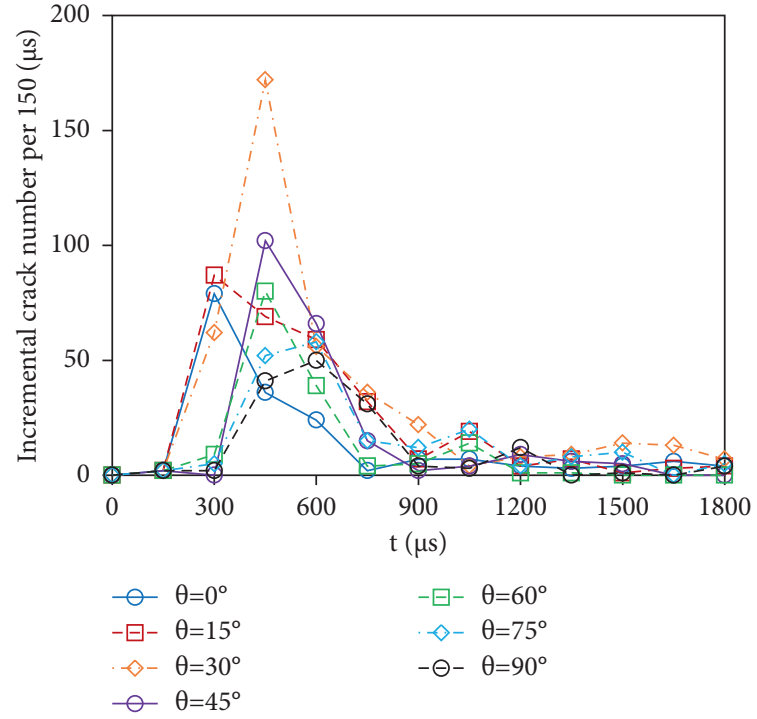

FIGURE 14: Comparison of the incremental crack number over time when different joint-slope angles are considered.

that when the impact velocity is $3.0 \mathrm{~m} / \mathrm{s}$ or $3.5 \mathrm{~m} / \mathrm{s}$, the cumulative number of cracks hardly increases before $300 \mu \mathrm{s}$. After $300 \mu \mathrm{s}$, it begins to grow slowly, and the growth stops after $900 \mu \mathrm{s}$, which indicates that the stress wave in the specimen is completely absorbed after $900 \mu \mathrm{s}$ and the damage process ends. Meanwhile, when the impact velocity is greater than $4 \mathrm{~m} / \mathrm{s}$, the cumulative number of cracks grows 
(a1)

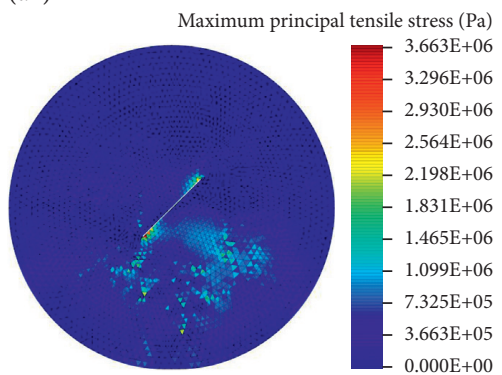

(b1)

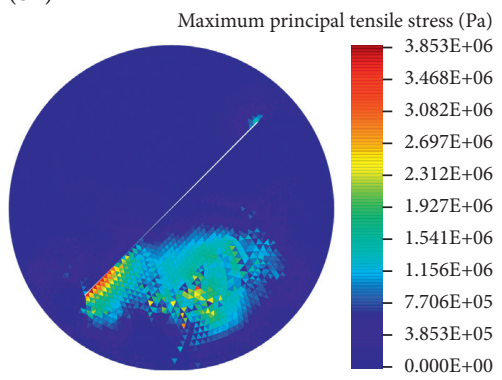

(a2)

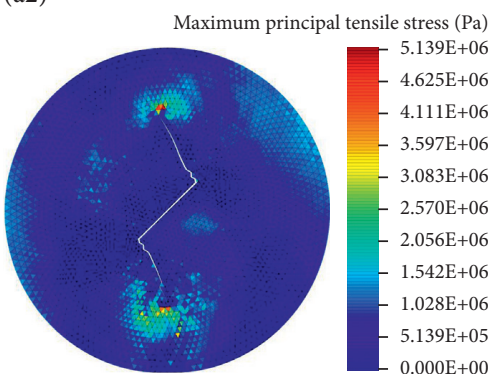

(a)

(b2)

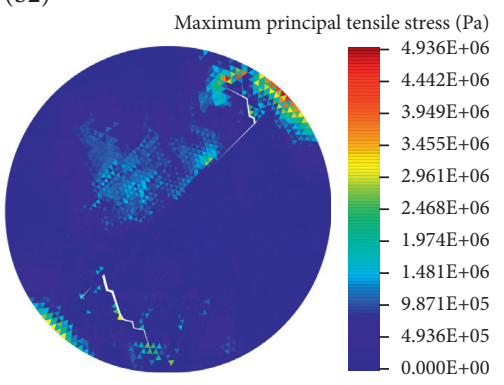

(a3)

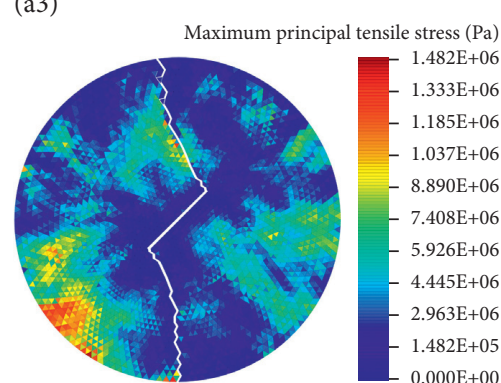

(b3)

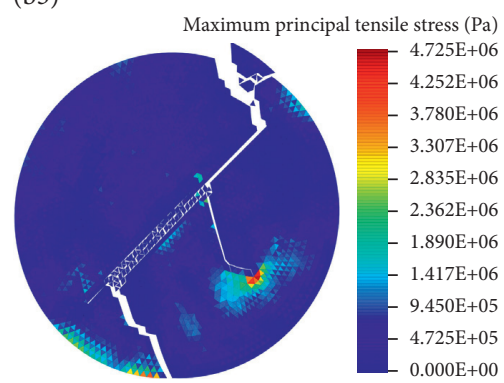

(b)

FIGURE 15: The simulated maximum principal tensile stress contours in (a) Case 8 and (b) Case $10\left(\theta=45^{\circ}\right.$ and $\left.v_{0}=3.5 \mathrm{~m} / \mathrm{s}\right)$. al and b1 are $200 \mu \mathrm{s}, \mathrm{a} 2$ and b2 are $400 \mu \mathrm{s}$, and $\mathrm{a} 3$ is $800 \mu \mathrm{s}$ and b3 is $1000 \mu \mathrm{s}$.

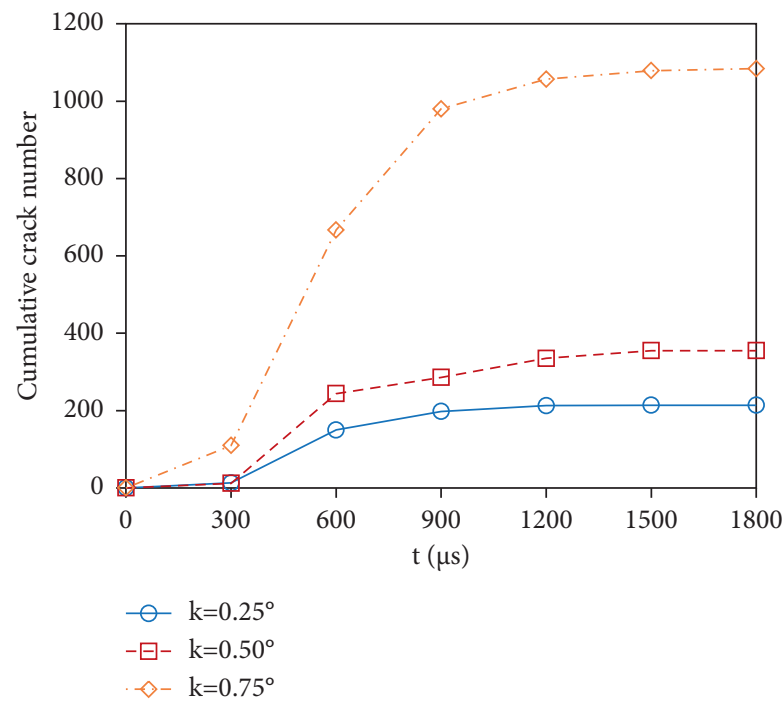

Figure 16: Comparison of the cumulative crack number over time when different joint connectivity rates are considered.

slowly before $300 \mu$ s but grows rapidly between $300 \mu$ s and $900 \mu \mathrm{s}$. The growth of cracks continues even after $900 \mu \mathrm{s}$, suggesting that the energy generated by the impact is not completely consumed when the specimen is penetrated, the stress wave is still propagating in the specimen, and the damage process is still continuing.

Figure 21 shows the comparison of the incremental number of cracks in the specimen under different impact velocities. It can be seen that, within the range of
$3.0 \sim 5.0 \mathrm{~m} / \mathrm{s}$, the number of cracks reaches the peak value at $300 \sim 450 \mu \mathrm{s}$, and the crack grows the fastest in the whole process; after that, the number of cracks in the $3.0 \mathrm{~m} / \mathrm{s}$ specimen drops rapidly, which indicates that the cracks no longer propagate. The greater the impact velocity is, the slower the decrease in the number of cracks is and the slower the energy dissipates. The comparison results suggest that the higher impact velocity leads to greater damage to the specimen. 


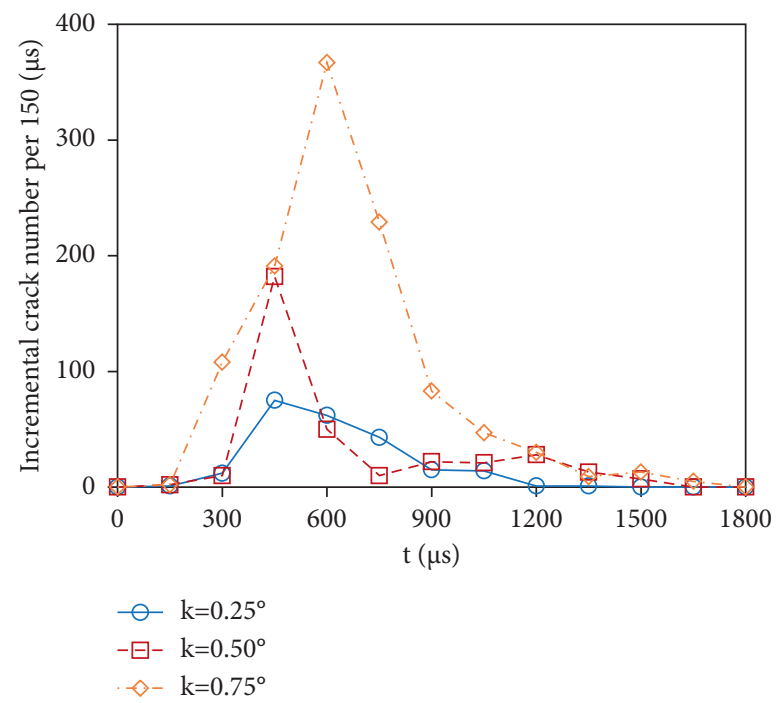

FiguRE 17: Comparison of the incremental crack number over time when different joint connectivity rates are considered.

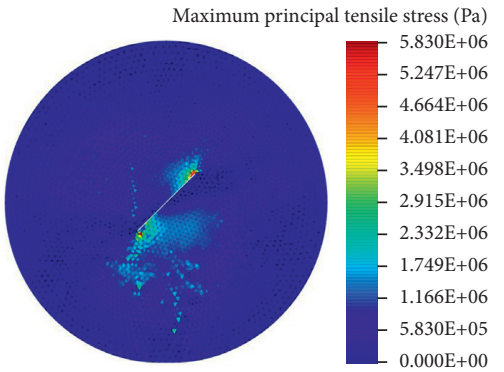

(a)

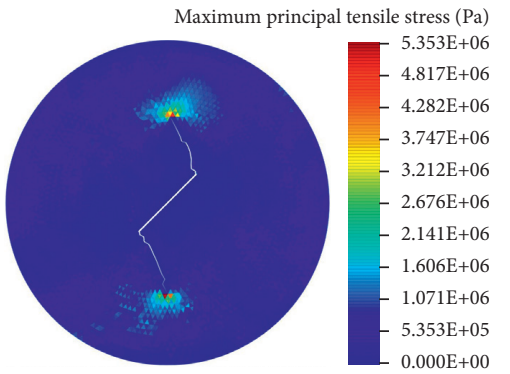

(b)

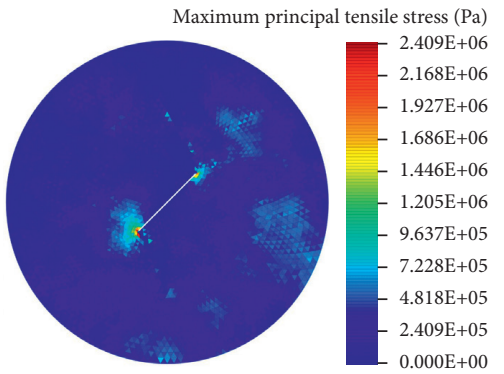

(c)

FIGURE 18: The simulated maximum principal stress contours in Case $11\left(\theta=45^{\circ}, \gamma=0.25\right.$, and $\left.v_{0}=3.0 \mathrm{~m} / \mathrm{s}\right)$. (a) $200 \mu \mathrm{s}$, (b) $700 \mu \mathrm{s}$, and (c) $900 \mu \mathrm{s}$.

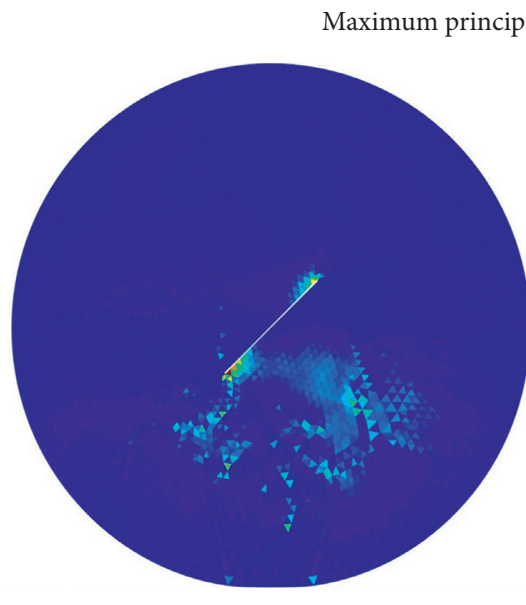

(a)

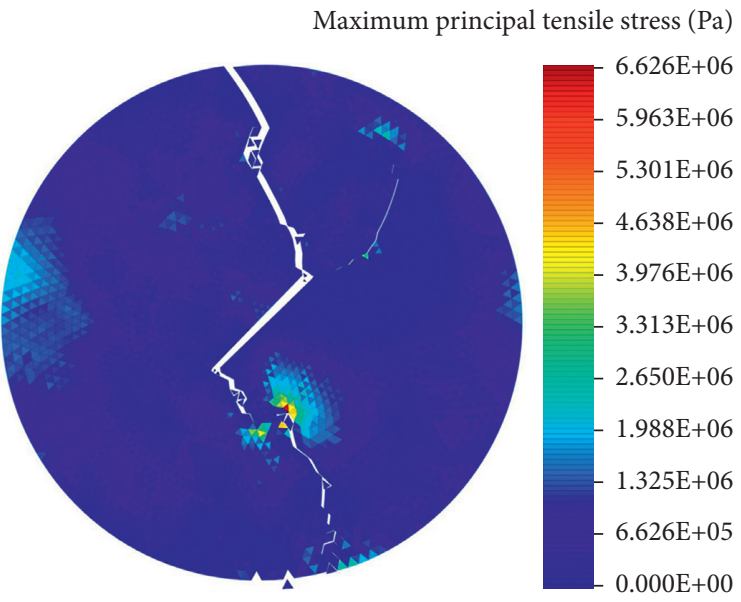

(b)

Figure 19: Continued. 


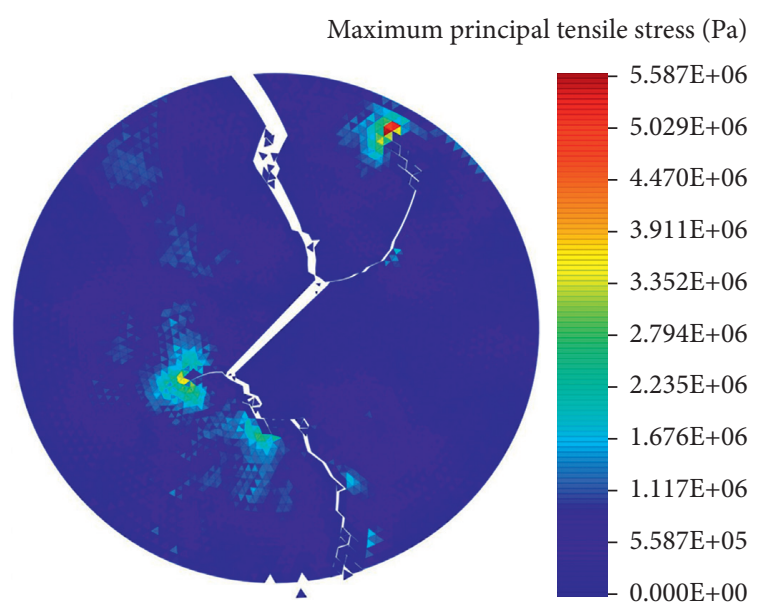

(c)

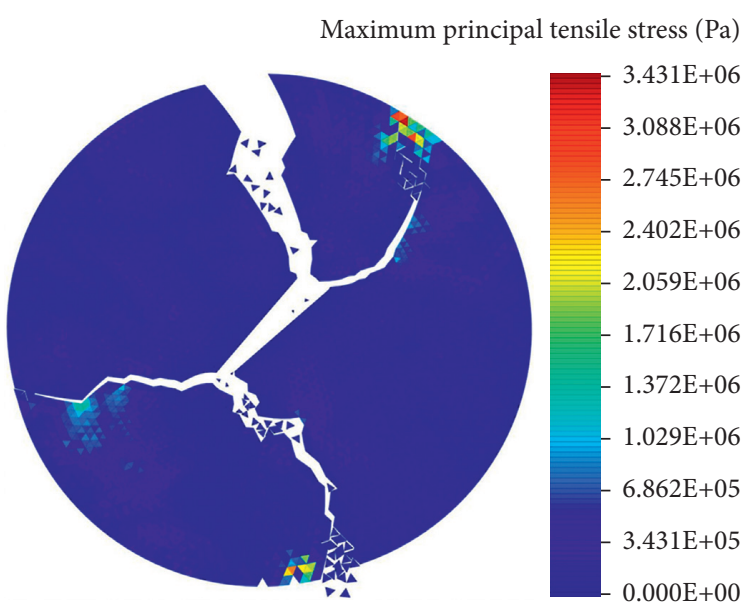

(d)

Figure 19: The simulated maximum principal stress contours in Case $14\left(\theta=45^{\circ}, \gamma=0.25\right.$, and $\left.v_{0}=5.0 \mathrm{~m} / \mathrm{s}\right) .(\mathrm{a}) 200 \mu \mathrm{s}$, (b) $1200 \mu \mathrm{s}$, (c) $1500 \mu \mathrm{s}$, and (d) $3000 \mu \mathrm{s}$

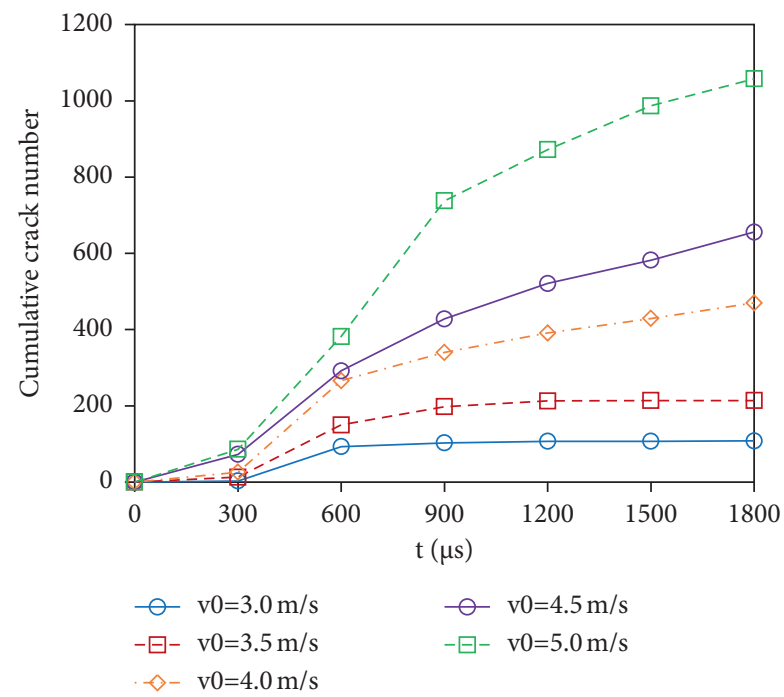

FIGURE 20: Comparison of the cumulative crack number over time when different impact velocities are considered.

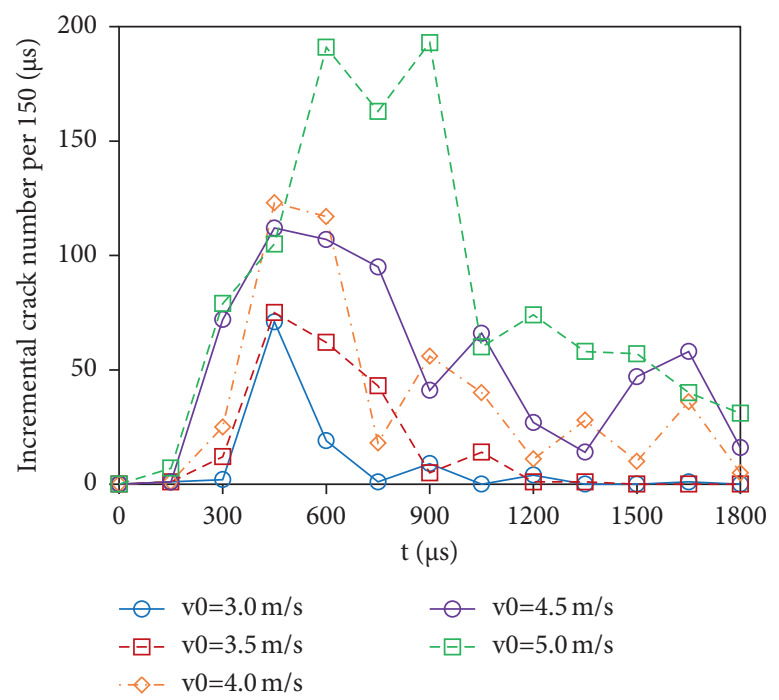

FIGURE 21: Comparison of the incremental crack number over time when different impact velocities are considered. 


\section{Conclusions}

In this paper, the effect of the preexisting crack in rocks on rockfall fragmentation is studied by using parallel DDA with virtual joints based on OpenMP. Although fruitful research regarding rockfalls has been conducted, the influence of preexisting cracks in rocks on the fragmentation of rockfalls is still worth studying. First, the parallel DDA with virtual joints is presented. Then, validation examples about both flattened and precrack Brazilian disc tests are provided. Then, DDA simulation cases of the rockfall impact fragmentation process are performed and validated with corresponding laboratory experiments in terms of crack propagation results. Further, the effects of joint-slope angle, joint connectivity rate, and impact velocity on fracture behaviors during rockfall impact fragmentation are discussed in detail. It is concluded that the higher impact velocity and joint connectivity rate tend to cause larger damages to the specimen. When the joint-slope angle increases from $0^{\circ}$ to $90^{\circ}$, the number of cracks tops in the range of $30^{\circ}$ to $45^{\circ}$.

The study in this paper still has space to improve. The cases used in this study are in a 2D situation. As a future study, the $3 \mathrm{D}$ analysis is desired since the $3 \mathrm{D}$ motion and rotation obviously affect the dynamic behavior of the rockfalls. In addition, the damping effect is another factor that should be addressed, especially in rockfalls. Further studies will focus on those mentioned aspects.

\section{Data Availability}

The data used to support the findings of this study are included within the article and available from the corresponding author upon request.

\section{Conflicts of Interest}

The authors declare that they have no conflicts of interest.

\section{Acknowledgments}

This study was funded by the National Key R\&D Program of China (No. 2017YFC1501001-03), the Natural Science Foundation of China (Nos. 41977233, 41902275, and 51708420, 41907251), and the Fuzhou Science and Technology Plan Project (No. 2019-G-45).

\section{References}

[1] L. K. A. Dorren, "A review of rockfall mechanics and modelling approaches," Progress in Physical Geography: Earth and Environment, vol. 27, no. 1, pp. 69-87, 2016.

[2] A. M. Ritchie, Evaluation of Rockfall and its Control, Washington State Highway Commission, Washington DC, USA, 1963.

[3] S. Ferlisi, L. Cascini, J. Corominas, and F. Matano, "Rockfall risk assessment to persons travelling in vehicles along a road: the case study of the Amalfi coastal road (southern Italy)," Natural Hazards, vol. 62, no. 2, pp. 691-721, 2012.

[4] O. Katz, P. Reichenbach, and F. Guzzetti, "Rock fall hazard along the railway corridor to Jerusalem, Israel, in the Soreq and Refaim valleys," Natural Hazards, vol. 56, no. 3, pp. 649-665, 2010.

[5] B. Palma, M. Parise, P. Reichenbach, and F. Guzzetti, "Rockfall hazard assessment along a road in the Sorrento Peninsula, Campania, southern Italy," Natural Hazards, vol. 61, no. 1, pp. 187-201, 2011.

[6] R. Salvini, M. Francioni, S. Riccucci, F. Bonciani, and I. Callegari, "Photogrammetry and laser scanning for analyzing slope stability and rock fall runout along the Domodossola?Iselle railway, the Italian Alps," Geomorphology, vol. 185, pp. 110-122, 2013.

[7] A. Shirzadi, L. Saro, O. Hyun Joo, and K. Chapi, "A GIS-based logistic regression model in rock-fall susceptibility mapping along a mountainous road: s," Natural Hazards, vol. 64, no. 2, pp. 1639-1656, 2012.

[8] S. G. Evans and O. Hungr, "The assessment of rockfall hazard at the base of talus slopes," Canadian Geotechnical Journal, vol. 30, no. 4, pp. 620-636, 1993.

[9] S.-S. Wu, "Rockfall evaluation by computer simulation," Transportation Research Record, vol. 1031, pp. 1-5, 1984.

[10] R. W. Day, "Case studies of rockfall in soft versus hard rock," Environmental and Engineering Geoscience, vol. III, no. 1, pp. 133-140, 1997.

[11] S. A. Schumm and R. J. Chorley, "The fall of threatening rock," American Journal of Science, vol. 262, no. 9, pp. 1041-1054, 1964.

[12] A. Valagussa, P. Frattini, and G. B. Crosta, "Earthquake-induced rockfall hazard zoning," Engineering Geology, vol. 182, pp. 213-225, 2014.

[13] A. Azzoni, G. La Barbera, and A. Zaninetti, "Analysis and prediction of rockfalls using a mathematical model," International Journal of Rock Mechanics and Mining Science \& Geomechanics Abstracts, vol. 32, no. 7, pp. 709-724, 1995.

[14] D. Bozzolo and R. Pamini, "Simulation of rock falls down a valley side," Acta Mechanica, vol. 63, no. 1-4, pp. 113-130, 1986.

[15] M. J. Kirkby and I. Statham, "Surface stone movement and scree formation," The Journal of Geology, vol. 83, no. 3, pp. 349-362, 1975.

[16] K. T. Chau, R. H. C. Wong, J. Liu, and C. F. Lee, "Rockfall hazard analysis for Hong Kong based on rockfall i," vol. 36, no. 5, pp. 383-408, 2003.

[17] G. B. Crosta and F. Agliardi, "A methodology for physically based rockfall hazard assessment," Natural Hazards and Earth System Sciences, vol. 3, no. 5, pp. 407-422, 2003.

[18] V. Labiouse, F. Descoeudres, and S. Montani, "Experimental study of rock sheds impacted by rock blocks," Structural Engineering International, vol. 6, no. 3, pp. 171-176, 2018.

[19] D. Peila, S. Pelizza, and F. Sassudelli, "Evaluation of brockfall restraining nets by full scale tests," Rock Mechanics and Rock Engineering, vol. 31, no. 1, pp. 1-24, 1998.

[20] M. Spadari, A. Giacomini, O. Buzzi, S. Fityus, and G. P. Giani, "In situ rockfall testing in New South Wales, Australia," International Journal of Rock Mechanics and Mining Sciences, vol. 49, pp. 84-93, 2012.

[21] C. R. Ruiz, J. Corominas, and O. Mavrouli, "An empirical approach to rockfall fragmentation," in Proceedings of the ISRM Regional Symposium-EUROCK 2015, Salzburg, Austria, 2015.

[22] Y. Okura, H. Kitahara, T. Sammori, and A. Kawanami, "The effects of rockfall volume on runout distance," Engineering Geology, vol. 58, no. 2, pp. 109-124, 2000.

[23] J. Corominas, O. Mavrouli, D. Santana, and J. Moya, "Simplified approach for obtaining the block volume distribution 
of fragmental rockfalls," in Proceedings of the A International Symposium on Landslides. B Landslides and Engineered Slopes, CRC Press, Taylor \& Francies Group, Banff, Canada, June 2012.

[24] J. Corominas, O. Mavrouli, and C. R. Ruiz, "Rockfall occurrence and fragmentation," in Proceedings of the Advancing Culture of Living with Landslides, pp. 75-97, Ljubljana, Slovenia, May 2017.

[25] F. Agliardi and G. B. Crosta, "High resolution three-dimensional numerical modelling of rockfalls," International Journal of Rock Mechanics and Mining Sciences, vol. 40, no. 4, pp. 455-471, 2003.

[26] J. Corominas, G. Matas, and C. R. Ruiz, "Quantitative analysis of risk from fragmental rockfalls," Landslides, vol. 16, no. 1, pp. 5-21, 2018.

[27] G. Matas, N. Lantada, J. Corominas, J. A. Gili, C. R. Ruiz, and A. Prades, "RockGIS: a GIS-based model for the analysis of fragmentation in rockfalls," Landslides, vol. 14, no. 5, pp. 1565-1578, 2017.

[28] C. R. Ruiz and J. Corominas, "Analysis of rockfalls by means of a fractal fragmentation model," Rock Mechanics and Rock Engineering, vol. 53, no. 3, pp. 1433-1455, 2019.

[29] C. R. Ruiz, J. Corominas, and O. Mavrouli, "A methodology to obtain the block size distribution of fragmental rockfall deposits," Landslides, vol. 12, no. 4, pp. 815-825, 2015.

[30] Y. Wang and F. Tonon, "Discrete element modeling of rock fragmentation upon impact in rock fall analysis," Rock Mechanics and Rock Engineering, vol. 44, no. 1, pp. 23-35, 2010.

[31] F. V. De Blasio and G. B. Crosta, "Fragmentation and boosting of rock falls and rock avalanches," Geophysical Research Letters, vol. 42, no. 20, pp. 8463-8470, 2015.

[32] T. Zhao, G. B. Crosta, S. Utili, and F. V. D. Blasio, "Investigation of rock fragmentation during rockfalls and rock avalanches via 3-D discrete element analyses," Journal of Geophysical Research: Earth Surface, vol. 122, no. 3, pp. 678-695, 2017.

[33] W. Shen, T. Zhao, G. B. Crosta, and F. Dai, "Analysis of impact-induced rock fragmentation using a discrete element approach," International Journal of Rock Mechanics and Mining Sciences, vol. 98, pp. 33-38, 2017.

[34] Y. Ye, K. Thoeni, Y. Zeng, O. Buzzi, and A. Giacomini, "Numerical investigation of the fragmentation process in marble spheres upon dynamic impact," Rock Mechanics and Rock Engineering, vol. 53, no. 3, pp. 1287-1304, 2020.

[35] G. H. Shi, "Discontinuous Deformation Analysis: A New Numerical Model for the Statics and Dynamics of Block systems," PhD Thesis, University of California, Berkeley, California, 1988.

[36] G. Chen, L. Zheng, Y. Zhang, and J. Wu, "Numerical simulation in rockfall analysis: a close comparison of 2-D and 3-D DDA," Rock Mechanics and Rock Engineering, vol. 46, no. 3, pp. 527-541, 2013.

[37] Y. H. Hatzor, A. A. Arzi, Y. Zaslavsky, and A. Shapira, "Dynamic stability analysis of jointed rock slopes using the DDA method: k," International Journal of Rock Mechanics and Mining Sciences, vol. 41, no. 5, pp. 813-832, 2004.

[38] X. Peng, G. Chen, P. Yu, Y. Zhang, and J. Wang, "Improvement of joint definition and determination in threedimensional discontinuous deformation analysis," Computers and Geotechnics, vol. 110, pp. 148-160, 2019.

[39] X. Peng, P. Yu, G. Chen, M. Xia, and Y. Zhang, "Development of a $\mathrm{c}$ method and its application to dynamic simulation of landslides involving solid-fluid i," Rock Mechanics and Rock Engineering, vol. 53, no. 1, pp. 113-131, 2019.
[40] J. Wu, C. H. Juang, and H. Lin, "Vertex-to-face contact searching algorithm for three-dimensional frictionless contact problems," International Journal for Numerical Methods in Engineering, vol. 63, no. 6, pp. 876-897, 2005.

[41] P. Yu, G. Chen, X. Peng, L. Guo, and Y. Zhang, "Extension and application of discontinuous deformation analysis with a damped contact spring model," International Journal of Rock Mechanics and Mining Sciences, vol. 123, Article ID 104123, 2019.

[42] P. Yu, Y. Zhang, X. Peng, G. Chen, and J. X. Zhao, "Distributed-spring edge-to-edge contact model for two-dimensional discontinuous deformation analysis," Rock Mechanics and Rock Engineering, vol. 53, no. 1, pp. 365-382, $2019 \mathrm{~b}$.

[43] H. Zhang, "A new algorithm to identify contact types between arbitrarily shaped polyhedral blocks for three-dimensional discontinuous deformation analysis," Computers and Geotechnics, vol. 80, pp. 1-15, 2016.

[44] L. Q. Choo, Z. Y. Zhao, H. M. Chen, and Q. Tian, "Hydraulic fracturing modeling using the discontinuous deformation analysis (DDA) method," Computers and Geotechnics, vol. 76, pp. 12-22, 2016.

[45] Y. Y. Jiao, X. L. Zhang, and J. Zhao, “Two-dimensional DDA contact constitutive model for simulating rock fragmentation," Journal of Engineering Mechanics, vol. 138, pp. 199-209, 2012.

[46] Q. Tian, Z. Y. Zhao, and H. R. Bao, "Block fracturing analysis using nodal-based discontinuous deformation analysis with the double minimization procedure," International Journal for Numerical and Analytical Methods in Geomechanics, vol. 38, pp. 881-902, 2014.

[47] Q. H. Wang, S. C. Li, L. P. Li, J. Wang, and Q. Zhang, "Crack propagation of jointed rock and application," Applied Mechanics and Materials, vol. 651-653, pp. 1143-1146, 2014.

[48] W. Zhu, Y. Chen, S. Li, F. Yin, S. Yu, and Y. Li, "Rock failure and its jointed surrounding rocks: a multi-scale grid meshing method for DDARF," Tunnelling and Underground Space Technology, vol. 43, pp. 370-376, 2014.

[49] X. Peng, "Parallel computing of three-dimensional discontinuous deformation analysis based on OpenMP," Computers and Geotechnics, vol. 106, pp. 304-313, 2019.

[50] X. Peng, G. Chen, P. Yu, Y. Zhang, H. Zhang, and L. Guo, “A full-stage parallel architecture of three-dimensional discontinuous deformation analysis using OpenMP," Computers and Geotechnics, vol. 118, Article ID 103346, 2020.

[51] P. Yu, X. Peng, G. Chen, L. Guo, and Y. Zhang, "OpenMPbased parallel two-dimensional discontinuous deformation analysis for large-scale simulation," International Journal of Geomechanics, vol. 20, 2020.

[52] Wang, Test Method for Tensile Strength and Fracture Toughness of Sandstone, Chengdu University of Technology, Chengdu, China, 2019.

[53] K. S. Ni, "Study on DDA Method for Fracture Failure Simulation," Master Thesis, Southwest University of Science and Technology, Mianyang, China, 2015.

[54] H. Haeri, K. Shahriar, M. F. Marji, and P. Moarefvand, "Experimental and numerical study of crack propagation and coalescence in pre-cracked rock-like disks," International Journal of Rock Mechanics and Mining Sciences, vol. 67, pp. 20-28, 2014.

[55] X. L. Zhang, Influence of Sing-Joint on the Impact-Fragmentation during rockfall-slope Interaction, Master Thesis, Fuzhou University, Fuzhou, China, 2020. 